\title{
Innate Immune Evasion of Alphaherpesvirus Tegument Proteins
}

\section{OPEN ACCESS}

Edited by:

Soren R. Paludan,

Aarhus University, Denmark

Reviewed by: Abel Viejo-Borbolla,

Hannover Medical School, Germany Anthony Lawrence Cunningham, Westmead Institute for Medical Research, Australia

*Correspondence: Anchun Cheng chenganchun@vip.163.com

†These authors have contributed equally to this work as first authors

Specialty section:

This article was submitted to

Viral Immunology,

a section of the journal

Frontiers in Immunology

Received: 06 April 2019

Accepted: 30 August 2019

Published: 13 September 2019

Citation:

Yang L, Wang $M$, Cheng A, Yang Q, Wu Y, Jia R, Liu M, Zhu D, Chen S,

Zhang $S$, Zhao $X$, Huang J, Wang $Y$,

Xu Z, Chen Z, Zhu L, Luo Q, Liu Y,

Yu Y, Zhang L, Tian B, Pan L,

Rehman MU and Chen X (2019)

Innate Immune Evasion of

Alphaherpesvirus Tegument Proteins.

Front. Immunol. 10:2196.

doi: 10.3389/fimmu.2019.02196

\section{Linjiang Yang ${ }^{1,2,3 \dagger}$, Mingshu Wang ${ }^{1,2,3 \dagger}$, Anchun Cheng ${ }^{1,2,3 *}$, Qiao Yang ${ }^{1,2,3}$, Ying $W^{1,2,3}$, Renyong Jia ${ }^{1,2,3}$, Mafeng Liu ${ }^{1,2,3}$, Dekang Zhu ${ }^{1,2,3}$, Shun Chen ${ }^{1,2,3}$, Shaqiu Zhang ${ }^{1,2,3}$, Xinxin Zhao ${ }^{1,2,3}$, Juan Huang ${ }^{1,2,3}$, Yin Wang ${ }^{1,2,3}$, Zhiwen $X^{1,2,3}$, Zhengli Chen ${ }^{1,2,3}$, Ling Zhu ${ }^{1,2,3}$, Qihui Luo ${ }^{1,2,3}$, Yunya Liu ${ }^{1,2,3}$, Yanling Yu ${ }^{1,2,3}$, Ling Zhang ${ }^{1,2,3}$, Bin Tian ${ }^{1,3}$, Leichang Pan ${ }^{1,3}$, Mujeeb Ur Rehman ${ }^{1,3}$ and Xiaoyue Chen ${ }^{1,2,3}$}

${ }^{1}$ Institute of Preventive Veterinary Medicine, Sichuan Agricultural University, Chengdu, China, ${ }^{2}$ Key Laboratory of Animal Disease and Human Health of Sichuan Province, Sichuan Agricultural University, Chengdu, China, ${ }^{3}$ Avian Disease Research Center, College of Veterinary Medicine, Sichuan Agricultural University, Chengdu, China

Alphaherpesviruses are a large family of highly successful human and animal DNA viruses that can establish lifelong latent infection in neurons. All alphaherpesviruses have a protein-rich layer called the tegument that, connects the DNA-containing capsid to the envelope. Tegument proteins have a variety of functions, playing roles in viral entry, secondary envelopment, viral capsid nuclear transportation during infection, and immune evasion. Recently, many studies have made substantial breakthroughs in characterizing the innate immune evasion of tegument proteins. A wide range of antiviral tegument protein factors that control incoming infectious pathogens are induced by the type I interferon (IFN) signaling pathway and other innate immune responses. In this review, we discuss the immune evasion of tegument proteins with a focus on herpes simplex virus type I.

Keywords: alphaherpesvirus, immune evasion, tegument protein, IFN, signaling pathway

\section{INTRODUCTION}

Herpesviruses are divided into three subfamilies, alpha-, beta- and gammaherpesviruses, all of which share a common viral morphology and approximately 40 conserved genes that are important for virus production. The alphaherpesvirus subfamily has a wide range of host (1). Herpes simplex virus 1 (HSV)-1, HSV-2, and varicella-zoster virus (VZV) belong to the human alphaherpesvirus subfamily, while veterinary alphaherpesviruses include bovine herpesvirus (BHV), pseudorabies virus (PRV), and waterfowl duck enteritis virus (DEV) (2).

Herpesviruses undergo two forms of replication, lytic replication, and latent infection. In the lytic replication cycle, the virus first enters a cell, and the viral DNA begins to replicate after the capsid DNA is released into the nucleus. Subsequently, after assembly and genome packaging, the capsid leaves the nucleus (3). The viral particles then undergo primary envelopment and de-envelopment at the nuclear envelope, with tegumentation and secondary envelopment occurring in the cytoplasm. Finally, the virions leave the host by exocytosis (Figure 2) (4-6). After some alphaherpesviruses replicate at the infection site, the nervous system is invaded by the fusion of some alphaherpesviruses with the neuronal membrane at the end of an axon. When alphaherpesvirus DNA enters ganglion cell nuclei, some viral particles immediately assemble into a chromatin structure, forming heterochromatin, and resulting in latent infection (7). Not all neuronal infections lead to chromatinization, and in some cases, neuronal infection leads to lytic replication. The occurrence of lytic replication may depend on both viral and cellular factors 
that are differentially expressed in distinct types of neurons. Epithelial cells are the primary sites for alphaherpesvirus infection and are typically asymptomatic. Infected humans or animals become carriers without symptoms, with the infection becoming detectable only when progeny viral particles intermittently leave the host cells through germination, exocytosis or induction of apoptosis, making herpesviruses difficult to monitor and control $(3,8)$.

During latent infection, the viral genome remains in the nucleus, wherein new viral particles accumulate due to periodic reactivation of the lytic replication cycle and are transported along axons into epithelial cells, resulting in symptomatic or asymptomatic shedding (1, 9-12). Lytic replication releases infectious particles that elicit a strong immune response, whereas in latent infection, viruses use various strategies to weaken the presentation of antigens and prolong the lifespans of host cells $(3,13)$. This approach is highly beneficial to the survival of viruses and the establishment of latent infections.

Alphaherpesviruses encode $\sim 8$ capsid proteins, 23 tegument proteins (Table 1), and 14 envelope proteins (14, 15). The tegument is located between the capsid and the envelope (Figure 1). The alphaherpesvirus tegument is a self-supporting structure consisting of thousands of densely packaged protein molecules. A proteomic analysis of extracellular HSV-1 by mass spectrometry identified 23 types of virus-encoded tegument proteins as well as some host cell enzymes, chaperones and structural proteins, some of which may be incorporated into the tegument (14). The density of the tegument at the icosahedral vertices of the HSV-1 capsid has been observed by cryo-electron microscopy (cryo-EM), which revealed C-capsid-specific and capsid-apex-specific components (16). More generally, in different subfamilies of herpesviruses, the components are referred to the capsid-associated tegument complex (CATC) (17). Tegument proteins are typically designated as internal or external tegument components depending on whether they preferentially bind to the capsid or viral membrane during entry and exit or on their fractionation behavior after virus decomposition with non-ionic detergents. Although the outer tegument appears to be amorphous, the inner layer has a partial icosahedral order because of its close relationship with the capsid (18). Tegument proteins promote viral replication by regulating genes transcription, halting cell protein synthesis, and destroying host innate immune responses. They can also provide scaffolds for viral particles assembly and create interaction networks to link viral capsids and envelope proteins $(1,19)$. In addition to the important role of some tegument proteins in viral particles for immune evasion, some other viral proteins are also important for their survival, as they prompte viral replication and participate

Abbreviations: HSV-1, Herpes simplex virus 1; BHV, Bovine herpesvirus; PRV, Pseudorabies virus; DEV, Duck enteritis virus; PRRs, Pattern recognition receptors; PAMPs, Pathogen-associated molecular patterns; IFN, Interferon; TLRs, Tolllike receptors; VZV, Varicella zoster virus; RIG-I, Retinoic acid-inducible gene I; MDA5, Melanoma differentiation-associated gene 5; TBK1, Tank-binding kinase 1; cGAS, cyclic GMP-AMP synthase; DDR, DNA damage response; ISGs, IFNstimulated genes; NF- $\kappa B$, Nuclear factor kappa B; TNF- $\alpha$, Tumor necrosis factor alpha; ZAP, Zinc finger antiviral protein; SVV, Simian varicella virus; SOCS, Suppressor of cytokine signaling; ATM, Ataxia telangiectasia mutated.
TABLE 1 | Alternative alphaherpesvirus tegument genes and their homologs.

\begin{tabular}{|c|c|c|}
\hline HSV-1/2 & VZV & PRV \\
\hline \multicolumn{3}{|c|}{ Tegument proteins involved in innate immune evasion } \\
\hline UL13 (VP18.8) & ORF47 & UL13 (VP18.8) \\
\hline UL36 (VP1-2) & ORF22 (p22) & UL36 \\
\hline UL37 & ORF21 & UL37 \\
\hline UL41 (VHS) & ORF17 & UL41 \\
\hline UL48 (VP16) & ORF10 & UL48 \\
\hline UL49 (VP22) & ORF9 & UL49 \\
\hline UL50 (dUTPase) & ORF8 & UL50 \\
\hline US3 & ORF66 & US3 \\
\hline US10 & ORF64/69 & / \\
\hline US11 & I & / \\
\hline RL1 (ICP34.5) & / & / \\
\hline RL2 (ICP0) & ORF61 & EPO (ICPO) \\
\hline RS1 (ICP4) & ORF62/71 (IE62) & IE180 (ICP4) \\
\hline UL54 (ICP27) & IE63 & UL54 (ICP27) \\
\hline \multicolumn{3}{|c|}{ Other tegument proteins } \\
\hline UL7 & ORF53 & UL7 \\
\hline UL11 & ORF49 & UL11 \\
\hline UL14 & ORF46 & UL14 \\
\hline UL16 & ORF44 & UL16 \\
\hline UL21 & ORF38 & UL21 \\
\hline UL23 & ORF36 & TK \\
\hline UL47 (VP13-14) & ORF11 & UL47 \\
\hline UL51 & ORF7 & UL51 \\
\hline UL55 & ORF3 & I \\
\hline US2 & I & / \\
\hline
\end{tabular}

in the viral immune process. For example, HSV-1 UL24 (20) has key roles in modulating innate immunity. However, this review focuses on the innate immune escape of tegument proteins. The mechanism by which tegument proteins facilitate innate immune evasion remains unclear.

Pattern recognition receptors (PRRs) are recognition molecules that are primarily expressed on the surface and in the intracellular compartments of innate immune cells. PRRs can recognize one or more pathogen-associated molecular patterns (PAMPs). The type I interferon (IFN) signaling pathway plays an important role in the innate immune response and is the first line of host defense against viruses (21). Among PRRs, Toll-like receptors (TLRs) were the first PAMP-detecting receptors to be discovered. Nucleic acids are detected by TLR3, TLR7, TLR8, and TLR9, which locate on the endosomal membrane $(22,23)$. TLRs detect PAMPs and subsequently recruit downstream binding proteins, such as bone marrow differentiation primary response protein 88 (MyD88), MyD88 binding protein-like protein (Mal), Toll/interleukin (IL)-1 receptor domain-containing adapter protein (TIRAP), and Toll/interleukin, which play important roles in the immune processes of HSV-1 infection. TLR3 can be activated by recognizing short double-stranded (dsRNA) and then further recruits and activates the adapter protein Toll/IL-1 receptor (TIR) domain-containing adaptor TRIF. Stimulation of the TLR3-TRIF signaling pathway activates 

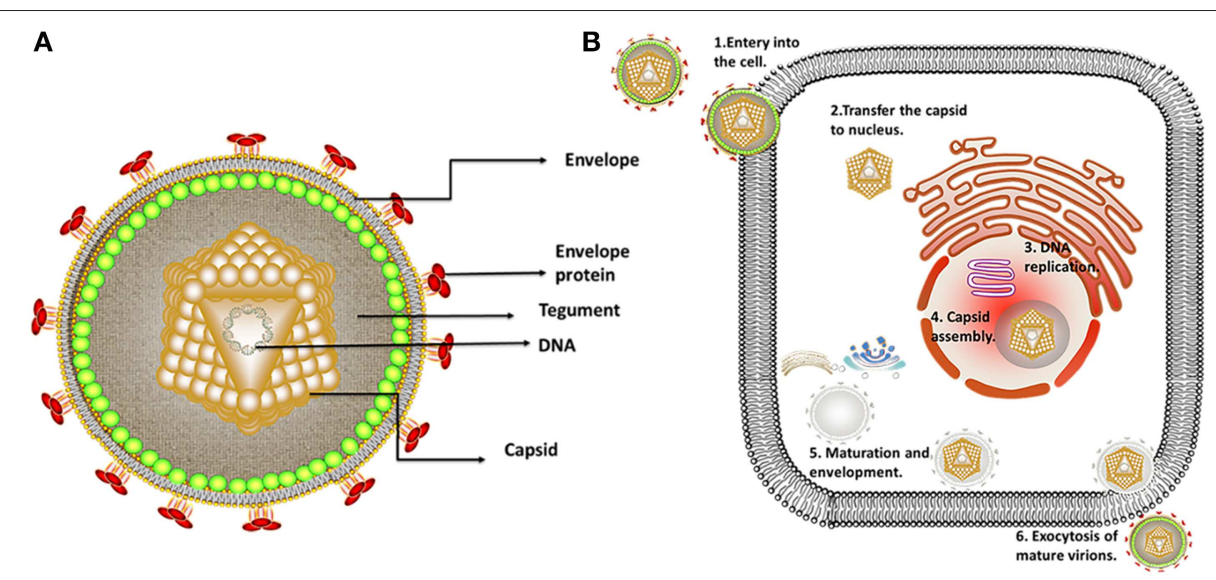

FIGURE 1 | Structure and replication process of herpes virus. (A) Structure of alphaherpesviruses. The viral particle structure of alphaherpesviruses includes the genome, tegument, envelope, and capsid. (B) The viral replication process of alphaherpesviruses. The viral replication process of alphaherpesviruses includes adsorption, replication, and assembly, secondary envelopment and exocytosis. Some inspiration for this figure was obtained from previous articles (3).

FIGURE 2 | MyD88, Mal, TIRAP,TIRAP-induced IFN- $\beta$ and TRAM. The formation of protein complexes of unique TBK1 and IKK inhibitors leads to activation of the transcription factors IRF3 and IRF7 and induction of IFN- $\beta$ expression. Viral proteins can degrade TLRs and interfere with TLR recognition. The ubiquitination activity of viral proteins can inhibit MyD88, Mal, and TRAF6. A series of strategies is used for virus immune evasion. Some inspiration for this figure was obtained from previous articles (4).

the transcription factors NF- $\mathrm{BB}$ and IFN regulator factor $3 / 7$ (IRF3/7), resulting in the translocation of NF- $\mathrm{KB}$ and IRF3/7 into the nucleus and the production of various cytokines, such as type I IFN (24). According to previous studies, HSV-1 can be detected by TLR2, TLR3, TLR4, and TLR9 (25). The cellular recognition of dsRNA or $5^{\prime}$-triphosphate dsRNA activates the expression of the retinoic acid-induced gene I (RIG-I) and melanoma differentiation-associated gene (MDA-5), resulting in homo-oligomerization of the mitochondrial antiviral signaling (MAVS) protein and activation of tank-binding kinase 1 (TBK1). In recent years, DNA sensors capable of detecting cytoplasmic DNA have been identified, including cyclic GMPAMP (CGAMP) synthase (cGAS), IFN- $\gamma$ inducible protein 16 (IFI16), DEAD-box polypeptide 41 (DDX41), DNA-dependent activator of IRF (DAI), and several proteins involved in the DNA damage response (DDR) $(21,26)$. Bacterial DNA, viral DNA, synthetic double-stranded DNA (dsDNA) and even dsDNA isolated from mammalian cells can be sensed in the cytosol if their lengths exceed 40-50 bp. The key DNA sensor cGAS, which binds to dsDNA and catalyzes the production of the second messenger $2^{\prime} 3^{\prime}$ - cGAMP. cGAMP then binds to the binding protein stimulator of the IFN gene (STING), causing 
a conformational change in the dimerization of STING. TBK1 phosphorylates the serine at position 366 of STING and then recruits IRF3 (27). In addition to the DNA sensor cGAS, RNA polymerase III (POL III) also functions as a DNA sensor, and cytosolic POL III acts as an innate PRR that recognizes abundant foreign DNA in the cytosol. POL III transcribes the exogenous AT-rich DNA into $5^{\prime}$-ppp RNA, which is recognized by the cytoplasmic RNA sensor RIG-I, thereby allowing downstream signaling via the adaptor MAVS to activate NF- $\kappa \mathrm{B}$ and IRF3. The activation of these proteins finally initiates host innate immune responses, including IFNs and proinflammatory cytokines (28-30). The binding of secretory IFNs to the homologous dimer receptors type I IFN receptor (IFNAR1) and type II IFN receptor (IFNAR2) induces the downstream Janus kinase (JAK)-signal transducer and activator of transcription factor (STAT) signaling pathway and antiviral IFN-stimulating gene (ISG) transcription (24).

Human and mouse genetic studies have found that type I IFN responses play an important role in controlling host innate immune responses to alphaherpesvirus infection. Human with mutations in STAT1, TLR3, or UNC-93B, whose gene products are involved in the production or responses of type I IFNs, are susceptible to HSV-induced encephalitis (31-34). Mouse models have demonstrated that type I IFNs are important for controlling acute alphaherpesvirus infection, and many gene products encoded by HSV can antagonize host type I IFN antiviral activity (35). Additionally, ISGs, such as ISG15 and $2^{\prime}-5^{\prime}$-oligonucleotide synthase (OAS1), have been shown to be important for controlling acute alphaherpesvirus infection in mice $(36,37)$. Defects in TLR3 increases susceptibility to HSV encephalitis, while impairment of POL III induces predisposition to VZV encephalitis. This specificity may due to the important role of TLR3 in recognizing HSV in the central nervous system, while POL III appears to be an important sensor for the AT-rich VZV genome (38). Carter-Timofte et al. identified mutations in the POL III gene, located in the subunits POLR3A and POLR3E, in two of eight patients by whole-exome sequencing. Functional analysis demonstrated impaired expression of antiviral and inflammatory cytokines in response to the POL III agonist Poly (dA: dT) and increased viral replication in patient cells compared to these features in controls (39).

In addition to the type I IFN signaling pathway, some other innate immune pathways are also involved $(40,41)$. Chromosome breaks at specific sites caused by HSV-1 infection interact with cellular pathways that identify and repair DNA damage, also known as the DDR. Studies have shown that the DDR plays an active role in antiviral activity $(42,43)$. Autophagy functions in regulating the activity of specific signals utilized by cells and can remove the threat of intracellular pathogens and prevent the damage or accumulation of long-lived and aggregation-prone proteins (44). Therefore, autophagy is an important aspect of innate immunity. Moreover, because viral infection also induces the formation of antiviral cytoplasmic granules known as stress granules (SGs), this process is closely associated with SG formation and type I IFN production (45).
TABLE 2 | Tegument proteins that inhibit the TLR pathway.

\begin{tabular}{llll}
\hline Protein & Virus & Function & References \\
\hline RL2 (ICP0) & HSV-1 & $\begin{array}{l}\text { Reduces the inflammatory } \\
\text { response triggered by TLR2 } \\
\text { Decreases MyD88 and Mal }\end{array}$ & (48) \\
US3 & HSV-1 & $\begin{array}{l}\text { Reduces the levels of TLR3 and } \\
\text { type I IFNs } \\
\text { Inhibits TLR2 signaling by } \\
\text { reducing TRAF6 } \\
\text { polyubiquitination } \\
\text { Reduces the expression of TLR2 } \\
\text { UL41 }\end{array}$ & and TLR3 \\
& HSV-2 & \\
& &
\end{tabular}

\section{IFN Induction and IFN-Dependent Signaling Pathways}

Tegument Proteins Inhibit the TLR Signaling Pathway

TLRs are type I transmembrane protein that recognize microorganisms invading the body and activate immune responses $(46,47)$ and are thus believed to play a key role in the innate immune system. Downstream binding proteins of the TLR signaling pathway include MyD88, Mal, TIRAP, TRIF, and TRAM. TBK1 is ubiquitinated and autophosphorylated, leading to activation of the transcription factors IRF3 and IRF7 and induction of IFN- $\beta$ expression (23) (Figure 2 and Table 2).

\section{TLR2}

The TLR2-dependent induction of type I IFNs occurs only in response to viral ligands. TLR2 can directly or indirectly promotes the synthesis and release of proinflammatory factors and enhances antiviral activities. Studies have also shown that infected cell protein 0 (ICP0) reduces the inflammatory response triggered by TLR2 during HSV-1 infection (48, 53, 54). van Lint and colleagues elucidated a process in which ICP0 promoted the degradation of TLR adapter molecules and inhibited inflammatory responses. ICP0 reduced the TLR-2mediated inflammatory response to HSV-1 infection, and ICP0 expression alone is sufficient to block the expression of TLR-2 in MyD88 adapter complexes through the E3 ligase function of ICP0 (55-57). Yao and Rosenthal found that the expression of TLR2 in VK2 epithelial cells transfected with the HSV-2 virion host shutoff (VHS) protein was reduced, consistent with the findings in HEK 293 cells (52).

\section{TLR3}

TLR2 has been reported to linked to the recognition of several DNA viruses, while dsRNA is a particularly potent nucleic acid intermediate that activates TLR3 (58). TLR3 is capable of inducing the expression of type I IFNs and inflammatory cytokines after detecting the dsRNA. TLR3-deficient fibroblasts produced much less type I IFN during HSV-1 infection than the control group, and impaired TLR3 signaling also resulted in high level of viral replication (59). Cellular proteasomal activity is required for this inhibitory activity. Peri and colleagues observed that pUS3 interferes with TLR3 recognition and MxA induction following inhibition of type I IFN mRNA in HSV-1 
infected cells (50). Similarly, Yao and Rosenthal found that the expression of TLR3 in VK2 epithelial cells transfected with the VHS protein was reduced, consistent with the findings in HEK 293 cells (52).

\section{MyD88 and mal}

MyD88 is an essential adapter molecule associated with inflammatory cytokines upon activation of all TLRs. The cascade pathway activates the transcription factor NF- $\kappa \mathrm{B}$ and promotes the production of the proinflammatory cytokines IL- $1 \beta$, IL-6, IL8 , IL-12, and monocyte chemotactic peptide 1 (MCP-1). Another MyD88-like protein, Mal, activates NF-kB, Jun amino-terminal kinase (JNK) and extracellular signal-regulated kinase-1 and-2. Mal can form homo- and heterodimers with MyD88 (60). van Lint showed that ICP0 can also decrease the level of MyD88 and Mal through its E3 ligase function (49).

\section{TRAF6}

The E3 ubiquitin ligase TNF receptor-associated factor 6 (TRAF6) interacts with TGF- $\beta$-activated kinase 1 (TAK1), subsequently activatingTAK1 (61). This interaction leads to activation of the IKK complex, which then phosphorylates the inhibitor of $\kappa \mathrm{B}$, causing $\kappa \mathrm{B}$ ubiquitination and degradation (62). The HSV-1 kinase pUS3 can inhibit the TLR-2 signaling pathway by reducing TRAF6 polyubiquitination, which depends on its kinase activity before or at the stage of TRAF6 ubiquitination $(51,63)$.

\section{Tegument Proteins Inhibit the RIG-I Signaling Pathway}

RIG-I and MDA-5 are members of the RIG-I-like receptor (RLR) family $(64,65)$ and can identify RNA viruses in cells and induce production of type I IFNs and immune factors (66). RIGI activates NF- $\kappa B$ and IRFs through MAVS (67). Kato's gene knockout experiments showed that loss of RIG-I or MAVS could severely inhibit the innate immune response of mice, resulting in highly increased viral replication (68) (Figure 3 and Table 3).

\section{RIG-I and MDA-5}

RIG-I and MDA-5 act as two cytoplasmic dsRNA sensors. RIGI primarily recognizes RNA containing $5^{\prime}$-triphosphate, while MDA- 5 typically recognizes dsRNAs $>2,000$ bp in length. RIGI and MDA-5 recruit MAVS to deliver signals to the kinase TBK1 and induce IкB kinase (IKKi), which phosphorylates

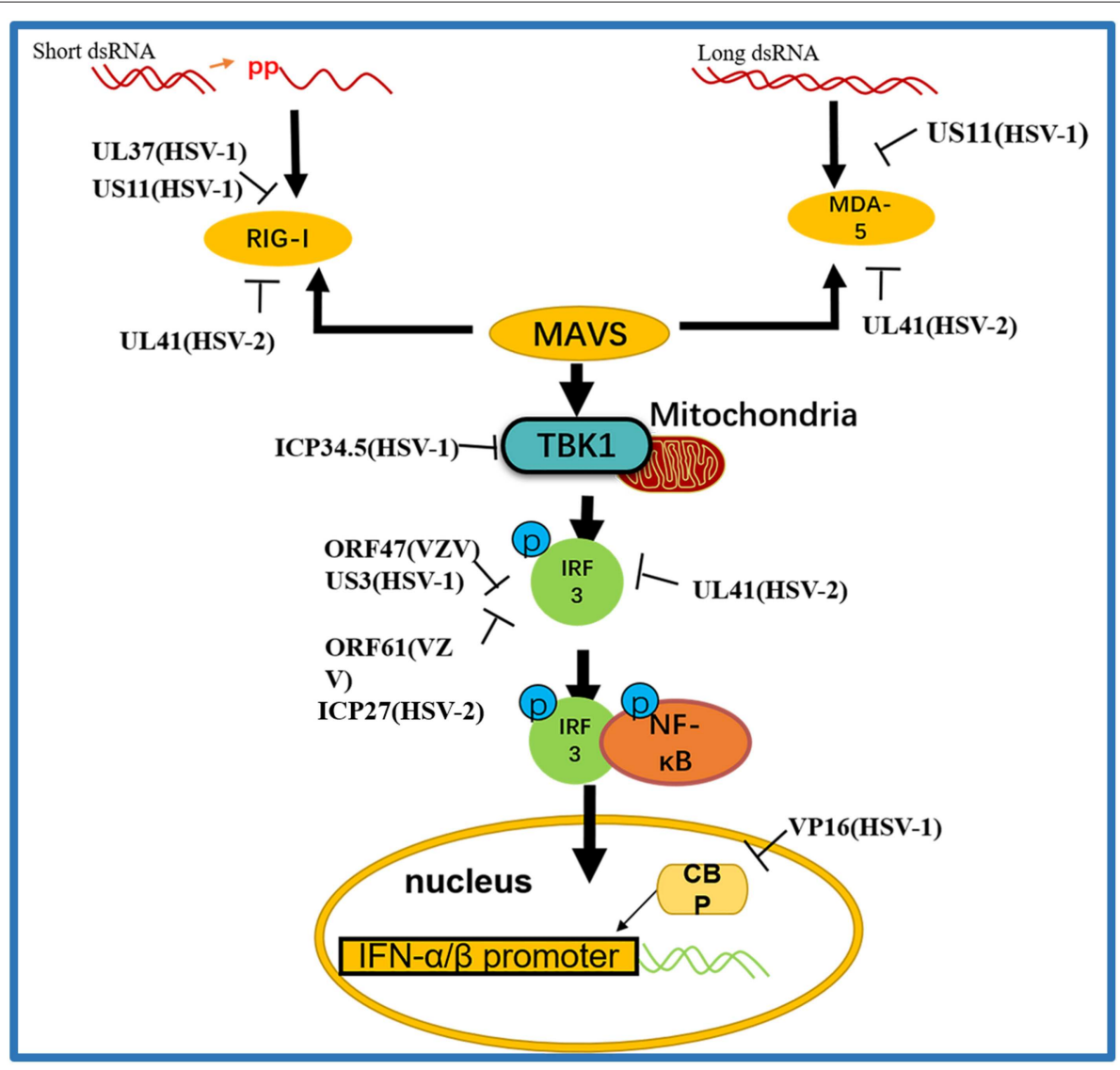

FIGURE 3 | A schematic diagram of the pathogen-derived molecules used to escape intracellular RNA sensing pathways. The sensors in the pathway include RIG-I and MDA-5, which can detect different RNA species, primarily those containing $5^{\prime}$ diphosphate or triphosphate or long dsRNA, respectively. Pathogen-derived degradative or inhibitory helper proteins inhibit RIG-I activation through direct binding to block the interaction between RIG-I and MAVS and prevent RIG-I from entering mitochondria. 
TABLE 3 | Tegument proteins that inhibit the RIG-I pathway.

\begin{tabular}{|c|c|c|c|}
\hline Protein & Virus & Function & References \\
\hline US3 & HSV-1 & $\begin{array}{l}\text { Interacts with and } \\
\text { hyperphosphorylates IRF3 to } \\
\text { prevent IRF3 activation }\end{array}$ & (69) \\
\hline US11 & HSV-1 & $\begin{array}{l}\text { Binds to RIG-I and MDA5 inhibits } \\
\text { their downstream signaling } \\
\text { pathway }\end{array}$ & (70) \\
\hline UL36 (VP1-2) & HSV-1 & $\begin{array}{l}\text { Deubiquitinates TRAF3 to } \\
\text { prevent the recruitment of TBK1 }\end{array}$ & (71) \\
\hline UL37 & HSV-1 & $\begin{array}{l}\text { Blocks RNA-induced activation } \\
\text { by targeting RIG-I }\end{array}$ & (67) \\
\hline \multirow[t]{2}{*}{ RL1 (ICP34.5) } & HSV-1 & Binds to and sequesters TBK1 & (72) \\
\hline & & $\begin{array}{l}\text { Controls IRF3 activation by } \\
\text { reversing translational shutoff } \\
\text { and sustaining the expression of } \\
\text { other IFN inhibitors }\end{array}$ & (73) \\
\hline UL46 & HSV-1 & $\begin{array}{l}\text { Blocks the interaction of TBK1 } \\
\text { and IRF3 and inhibits the } \\
\text { dimerization of TBK1 }\end{array}$ & (74) \\
\hline UL48 (VP16) & HSV-1 & $\begin{array}{l}\text { Blocks MAVS-Pex-mediated } \\
\text { early ISG production }\end{array}$ & (75) \\
\hline ORF61 & VZV & Degrades activated IRF3 & (76) \\
\hline ORF47 & VZV & $\begin{array}{l}\text { Prevents IRF3 homodimerization } \\
\text { and subsequent induction of } \\
\text { IFN- } \beta \text { and ISG15 }\end{array}$ & (77) \\
\hline UL41 & HSV-2 & $\begin{array}{l}\text { Inhibits RIG-I and MDA-5 as well } \\
\text { as IRF3 dimerization and } \\
\text { translocation }\end{array}$ & (52) \\
\hline ORF62(IE62) & VZV & $\begin{array}{l}\text { Blocks the phosphorylation of } \\
\text { serine residues 396, 398, and } \\
402 \text { in IRF3 }\end{array}$ & (78) \\
\hline UL54(ICP27) & HSV-2 & $\begin{array}{l}\text { Inhibit IRF3 phosphorylation and } \\
\text { nuclear translocation }\end{array}$ & (79) \\
\hline
\end{tabular}

both IRF3 and IKB kinase beta (IKK $\beta$ ) and then activates the NF- $\kappa \mathrm{B}$ signaling pathway (80). Once activated, IRF3 transfers to the nucleus and binds to positive regulatory domains I and III of the IFN $\beta$ promoter to induce IFN $\beta$ expression. Through coimmunoprecipitation analyses, Xing and colleagues demonstrated that in HSV-1 infected cells, the pUS11 C-terminus interacts with endogenous RIG-I and MDA- 5 through an RNA binding domain. HSV-1 pUS11 can block IFN- $\beta$ production and inhibit downstream signaling pathway activation by binding to RIG-I and MDA-5 (70). Zhao and colleagues observed that HSV-1 pUL37 is a deaminase protein that blocks RNA-induced activation by targeting RIG-I. Upon interacting with pUL37, RIG-I activation was inhibited (67). Yao and his colleague found that HSV-2 pUL41/VHS can inhibit the expression of RIG-I and MDA-5, thereby facilitating virus to evade host innate immune responses (52).

\section{MAVS}

Activated RIG-I and MDA-5 induce downstream signal transduction by binding to MAVS. The N-terminus of MAVS contains a CARD-like domain that binds to RIG-I and MDA-5, and through a CARD-CARD interaction to activate NF- $\mathrm{KB}$ and
IRFs. MAVS is located in the outer mitochondrial membrane and interacts with RIG-I and MDA-5 to self-oligomerize (81). Peroxisome MAVS (MAVS-Pex) signaling has been reported to trigger the rapid production of IFN-dependent ISG in response to invasive pathogens (82). For example, pUL48/VP16, a tegument protein encoded by HSV-1, blocks the early production of ISG mediated by MAVS-Pex and inhibits the early innate immune signaling of peroxisomes (75).

\section{TRAF3}

TRAF3 is an important molecule in the RLR signaling pathway. The downstream kinases TBK1 and IкB kinase $\varepsilon$ of RIG-I are recruited by the K63-mediated multiubiquitination of TRAF3, which results in IRF3 phosphorylation and the subsequent production of type I IFNs (83). pUL36 ubiquitin-specific protease has been shown to deubiquitinate TRAF3 and block the recruitment of the downstream adaptor TBK1 to decrease the production of IFN- $\gamma$ during HSV-1 infection (71).

\section{TBK1}

As an IкB kinase-related kinase, TBK1 can phosphorylate a variety of substrates that are involved in various cellular processes (84). After DNA and RNA sensors detecting nucleic acids, TBK1 is activated. TBK1 triggers the phosphorylation of IRF3, the activation of NF- $\mathrm{KB}$ and the expression of type I IFNs. HSV1 ICP34.5 is a neurotoxic factor with multiple functions and plays a crucial role in viral pathogenesis (85). Previous studies have reported that HSV-1 ICP34.5 can regulate IFN production by binding to and isolating TBK1 (72) and suppressing the induction of the ISG56 promoter by TBK1. Recently, study found that HSV-1 pUL46 interacted with TBK1 and reduced TBK1 activation and its downstream signaling. The results showed that pUL46 impaired the interaction between TBK1 and IRF3 and downregulated the activation of IRF3 by inhibiting the dimerization of TBK1 to reduce the production of type I IFN and immunostimulatory DNA (74).

\section{IRF3}

Activated IRF3 is essential for the effective transcription of type I IFNs, and IRF3 plays an important role in RLR-independent signal transduction. Activated IRF3 dimerizes and migrates to the nucleus, wherein it identifies specific sequence-based IFN stimulus response elements in the regulatory regions of target genes (86). Studies have shown that US3 protein expression can significantly inhibit the activation of IFN- $\gamma$, IFN stimulatory response element (ISRE) promoters and transcription of IFN, ISG54, and ISG56 via the neurovirus Sendai virus (SEV) (87). In addition, the SEV-induced dimerization and nuclear translocation of IRF3 have been shown to be blocked by pUS3. pUS3 can interact with and hyperphosphorylate IRF3 at serine 175, thus blocking IRF3 activation (69). Manivanh provided evidence that ICP 34.5 controlled IRF3 activation via its ability to regulate translational shutoff reversal and by maintaining the expression of other IFN inhibitors encoded by viruses (73). The VZV immediate-early protein ORF61, a protein homologous to HSV-1 ICP0, attenuates the IRF3-mediated innate immune response through degradation of activated 
IRF3 (76). Vandevenne observed that during VZV infection, the VZV kinase ORF47, a protein homologous to UL13, can atypically inhibit the phosphorylation of IRF3, which blocks the homodimerization and induction of target genes such as IFN- $\beta$ and ISG15 (77). VZV ORF62/IE62 is a protein homologous to HSV ICP4. Sen and colleagues found that the inhibition mediated by VZV IE62 may be the three serine residues (396, 398, and 402) on IRF3 were inhibited, thus blocking the downstream signal transduction mediated by IRF3 (78). Additional studies revealed that HSV-2 ICP27 directly associates with IRF3 and inhibits its phosphorylation and nuclear translocation, resulting in the inhibition of IFN- $\beta$ induction (79) (Table 2).

\section{Tegument Proteins Inhibit the NF-кB Signaling Pathway}

The NF- $\mathrm{B}$ signaling pathway is an important factor in antiviral immunity $(88,89)$ that promotes the expression of proteins contributing to viral replication and induces specific and adaptive immune responses (90). PPRs, TLRs, and RLRs can all lead to the induction of the NF- $\kappa \mathrm{B}$ signaling pathway.

During HSV-1 infection, pUL48 can block IFN- $\beta$ production by inhibiting NF- $\mathrm{B}$ activation and interfering with the IRF3 recruitment of its coactivator CBP (91). The ORF61 protein of $\mathrm{VZV}$ and simian varicella virus (SVV) is involved in immune evasion and can prevent IкB- $\alpha$ from ubiquitination. Travis further demonstrated that SVV ORF61 can interact with $\beta$-TrCP, a subunit of the SCF ubiquitin ligase complex, to mediate the degradation of IкB- $\alpha$ (92). Sloan and colleagues observed that VZV ORF61 could inhibit the activity of the NF- $\kappa$ B reporter induced by tumor necrosis factor alpha (TNF- $\alpha$ ). In addition, ORF61 mutation experiments revealed that the E3 ubiquitin ligase domain was necessary to inhibit the NF- $\kappa \mathrm{B}$ pathway (93). During HSV-1 infection, ICP0 can interact with p65 and p50 and degrade the proteasomal protein p50 to block the nuclear translocation of p 65 and reduce NF-кB-dependent genes expression (94). In contrast, another study showed that ICP0 can also ubiquitinate I $\kappa \mathrm{B}-\alpha$ and activate the transcription of NF-кB target genes (95). In addition, the replication of HSV1 can be directly enhanced by stimulation of NF- $\kappa \mathrm{B}$, with recruitment of the ICP0 promoter by NF- $\kappa$ B activating the transcription and replication of ICP0 (96). The HSV-1 protein kinase US3 hyperphosphorylated p65 at serine 75 and blocked its nuclear translocation, significantly inhibiting NF- $\kappa$ B activation and decreasing the expression of the inflammatory chemokine IL-8 $(97,98)$ (Figure 2 and Table 4).

\section{Tegument Proteins Inhibit the DNA Sensor Signaling Pathway}

In recent years, substantial advances have been made in research on DNA sensors. Several important cytoplasmic DNA sensors have been identified and characterized, providing insights into the mechanisms of sensor signaling pathways (21)

(Figure 4 and Table 5).

\section{$c G A S$}

Among the DNA sensors, cGAS, a nucleotidyltransferase, is responsible for identifying various DNA ligands present in
TABLE 4 | Tegument proteins that inhibit the NF-кB pathway.

\begin{tabular}{|c|c|c|c|}
\hline Protein & Virus & Function & References \\
\hline UL48 (VP16) & HSV-1 & $\begin{array}{l}\text { Inhibits NF-кB activation and } \\
\text { interferes with the } \\
\text { IRF-3-mediated recruitment of its } \\
\text { coactivator CBP }\end{array}$ & (91) \\
\hline \multirow[t]{2}{*}{ ORF61 } & SW & $\begin{array}{l}\text { Prevents } \mathrm{I}_{\kappa \mathrm{B} \alpha} \text { ubiquitination and } \\
\text { interacts with } \beta \text { - } \operatorname{TrCP}\end{array}$ & (92) \\
\hline & VZV & $\begin{array}{l}\text { Inhibits TNF- } \alpha \text {-induced NF-кB } \\
\text { reporter activity }\end{array}$ & (93) \\
\hline RL2 (ICP0) & HSV-1 & $\begin{array}{l}\text { Interacts with p50 and p60 and } \\
\text { degrades the proteasomal } \\
\text { protein p50 }\end{array}$ & (94) \\
\hline \multirow[t]{2}{*}{ US3 } & HSV-1 & 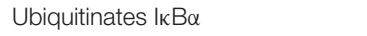 & (95) \\
\hline & & $\begin{array}{l}\text { Hyperphosphorylates p65 at } \\
\text { serine } 75 \text { and blocks p65 } \\
\text { nuclear translocation }\end{array}$ & (97) \\
\hline
\end{tabular}

certain cell types. cGAS is activated by binding to cytosolic dsDNA and uses ATP and GTP to produce cGAMP through its enzymatic activity (107). Huang and colleagues showed that VP22 encoded by the HSV-1 UL49 gene is a tegument protein. VP22 participates in the innate immune antiviral process by inhibiting the enzymatic activity of cGAS and thus antagonizing the DNA-mediated innate immune signaling pathway (103). Zhang et al. discovered the innate immune evasion mechanism of the HSV-1 pUL37 deaminase protein and revealed that the human and mouse cGAS proteins (but not the nonhuman primate cGAS proteins) are targets for UL37 deamidation, promoting the lytic replication of HSV-1 (105).

\section{STING}

When STING is activated, it recruits TBK1, activates IRF3 and induces the production of IFN- $\beta$ (103). As a broad antimicrobial factor, the DNA sensor STING antagonizes HSV by activating type I IFNs and proinflammatory responses upon sensing foreign DNA or non-canonical cyclic dinucleotides, the latter of which are synthesized by cGAS (108). Previous data suggested that ICP0 blocks the STING pathway (100). The transcription factor IRF3, a primary component of the STING pathway, is known to be blocked by ICP0 $(101,102)$, although the associated mechanism is unclear. Deschamps and colleagues showed that STING was degraded in cells expressing HSV-1 pUL46, which blocked the accumulation of STING transcripts (100). ICP27 interacted with TBK1 and STING in a manner that was dependent on TBK1 activity and the RGG motif in ICP27. Thus, HSV-1 inhibits the expression of type I IFNs in human macrophages through ICP27-dependent targeting of the TBK1-activated STING signalsome (106).

\section{IFI16}

IFI16, a member of the PYHIN protein family, was originally reported to be a cytosolic DNA sensor and has been implicated in the type I IFN response to HSV-1 (109-111). IFI16 localizes in the nuclei of many types of cells, making it a potential 


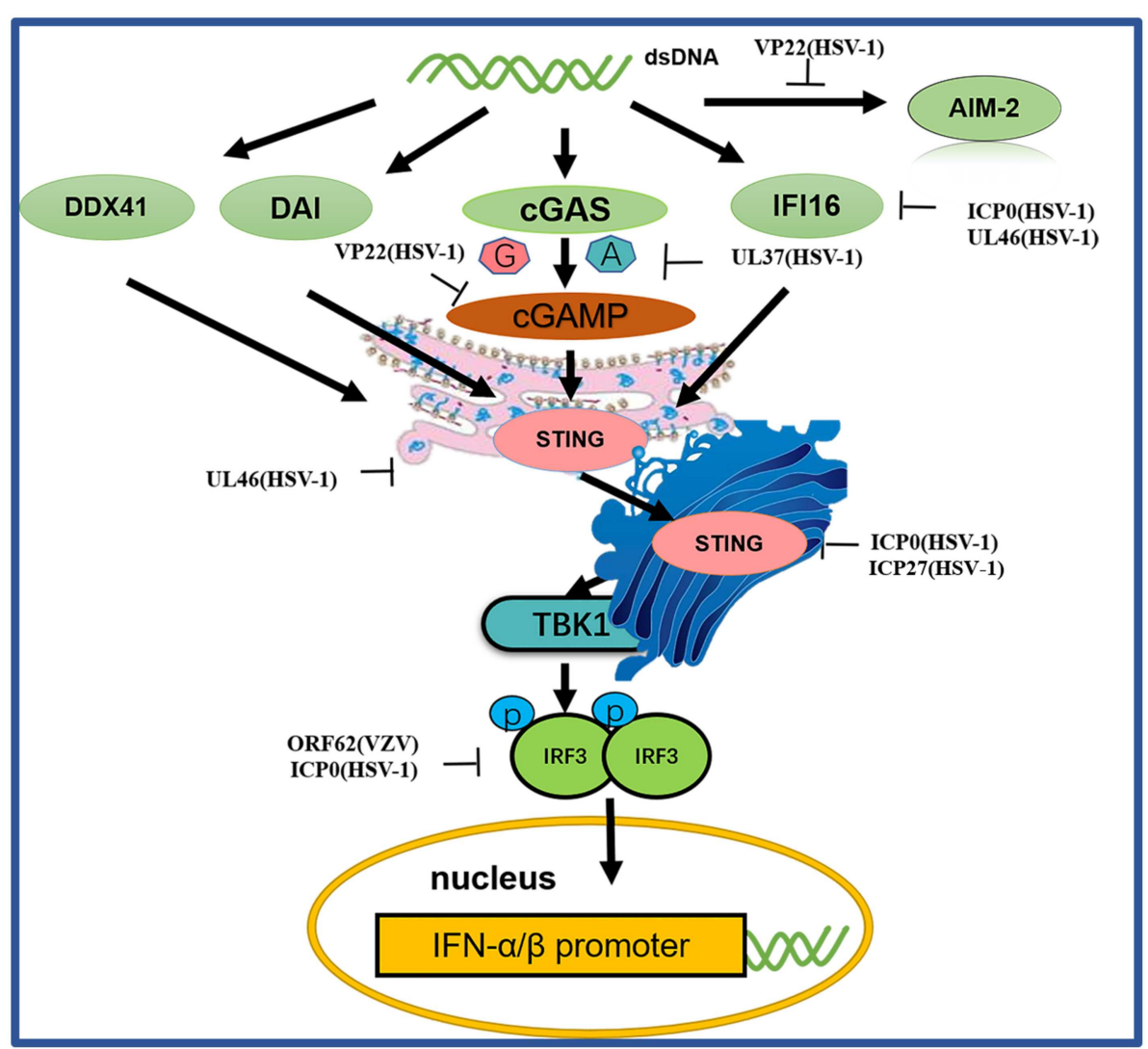

FIGURE 4 | A schematic diagram of pathogen-derived molecules used to escape intracellular DNA sensing pathways. The primary sensor of cytoplasmic DNA is cGAS, which is responsible for activating the binding protein STING. Pathogen-mediated degradation targets cGAS to prevent it from binding to DNA or to inhibit its catalytic activity. At the same time, pathogen invaders also degrade cGAMP and bacterial circulating dinucleotides. IFI16 positively affects the activation of the cGAS-STING pathway. Other DNA sensors, such as DAI and AIM2, are also viral factors that block DNA binding and downstream pathway activation. Viral proteolytic enzymes can decompose and degrade these factors; blocking their translocation and preventing their interaction from the downstream signaling protein TBK1, thus hindering STING function.

candidate for sensing HSV-1 DNA in the nucleus (112). Studies have shown that HSV ICP0 triggers IFI16 degradation, thereby inhibiting additional signaling and IRF3 activation $(99,113)$. Deschamps and colleagues also showed that IFI16 is degraded in cells constitutively expressing HSV-1 pUL46, which blocks the accumulation of IFI16 transcripts (104).

\section{Other DNA sensors}

Before the study of cGAS, proteins such as DAI, DDX41, DNA-dependent protein kinase (DNA-pk) and AIM2 were identified as cytosolic DNA sensor candidates (114). Although these proteins were reported to inhibit viral replication, further studies have shown that they are not necessarily involved in the DNA-induced responses in many human cells, suggesting that they may play a redundant or cell- typespecific role. HSV-1 AIM2-dependent inflammatory activation has been shown to be inhibited by the HSV-1 tegument protein VP22. VP22 can interact with AIM2 and prevent AIM2 oligomerization, which is the first step in AIM2 inflammasome activation (115).

\section{Tegument Proteins Inhibit IFN-Stimulated Genes}

Type I IFNs triggers numerous ISGs, such as viperin, zinc finger antiviral protein (ZAP), tetherin, dsRNA-dependent protein kinase (PKR), and OAS. Different combinations of ISGs can enhance the signaling transduction of type I IFNs and the antiviral activity of host to inhibit viral replication $(21,116)$ (Figure 5 and Table 6).

\section{Viperin}

Viperin was first to be identified as a highly conserved protein that can induce IFN- $\gamma$ protein production and is comprised of 361 amino acids. A number of studies have shown that viperin is directly induced by human cytomegalovirus and exhibits low expression (124). The viperin gene (also known as CIG5 or RASD2) can also be classified as an antiviral ISG that restricts the replication of DNA and RNA viruses (125). However, it is unclear whether viperin plays a role in HSV-1 infection. HSV-1 pUL41 can degrade host mRNA by cutting it at a preferential site, and UL41 promotes the replication of HSV-1 by degrading viperin mRNA (117). 


\section{ZAP}

In addition to viperin, ZAP is an antiretroviral factor that was originally identified in rats. Viruses that contain ZAP response elements (ZREs) in their RNA are sensitive to ZAP. Studies have shown that human ZAP (hZAP) has no inhibitory effect on the replication of HSV-1, and as an antagonist of hZAP, HSV-1 pUL41/VHS can degrade hZAP mRNA (118).

\section{Tetherin}

Tetherin (BST-2 or CD317) is a membrane glycoprotein that can induce the production of IFNs and effectively exert antiviral activity by inhibiting the release of many envelope viruses (126).

TABLE 5 | Tegument proteins that inhibit the DNA sensor signaling pathway.

\begin{tabular}{|c|c|c|c|}
\hline Protein & Virus & Function & References \\
\hline \multirow[t]{2}{*}{ RL2 (ICPO) } & HSV-1 & $\begin{array}{l}\text { Targets IFI16 degradation, } \\
\text { inhibiting additional signaling and } \\
\text { IRF-3 activation }\end{array}$ & (99) \\
\hline & & $\begin{array}{l}\text { Blocks STING and the } \\
\text { transcription factor IRF3 }\end{array}$ & $(100-102)$ \\
\hline UL49 (VP22) & HSV-1 & $\begin{array}{l}\text { Inhibits the enzymatic activity of } \\
\text { cGAS }\end{array}$ & $(103)$ \\
\hline UL46 (VP11-12) & HSV-1 & $\begin{array}{l}\text { Blocks STING and IFI16 } \\
\text { transcript accumulation }\end{array}$ & $(104)$ \\
\hline UL37 & HSV-1 & Deamidates cGAS proteins & $(105)$ \\
\hline UL54 (ICP27) & HSV-1 & $\begin{array}{l}\text { Targets the TBK1-activated } \\
\text { STING signalsome }\end{array}$ & $(106)$ \\
\hline
\end{tabular}

Helen showed that overexpression of tetherin can inhibit the replication of HSV-1 and that HSV-1 pUL41/VHS can deplete tetherin mRNA via its mRNA degradation function (120).

\section{PKR}

Binding of dsRNA activates PKR, which then phosphorylates the $\alpha$ subunit of eIF2 $\alpha$, resulting in translational inhibition (127). HSV-1 pUS11, a late-stage gene, inhibits PKR activation by binding to both dsRNA and PKR to prevent them from binding to each other (123), and then inhibits PKR phosphorylation. Other studies have shown that during early infection, the HSV1 pUL41 VHS RNase protein degrades RNAs that activate PKR. The VHS RNase protein and mitogen-activated protein kinase act cooperatively to block the activation of PKR (121).

TABLE 6 | Immune evasion of tegument proteins through ISGs.

\begin{tabular}{llll}
\hline Protein & Virus & Function & References \\
\hline UL41 & HSV-1 & Degrades viperin mRNA & $(117)$ \\
& & Degrades hZAP mRNA & $(118)$ \\
& Reduces the accumulation of & $(119)$ \\
& IFIT3 mRNA & \\
& & Depletes tetherin mRNA & $(120)$ \\
& & Block the activation of PKR & $(121)$ \\
US11 & HSV-1 & Inhibits OAS & $(122)$ \\
& & Inhibits PKR & (123)
\end{tabular}

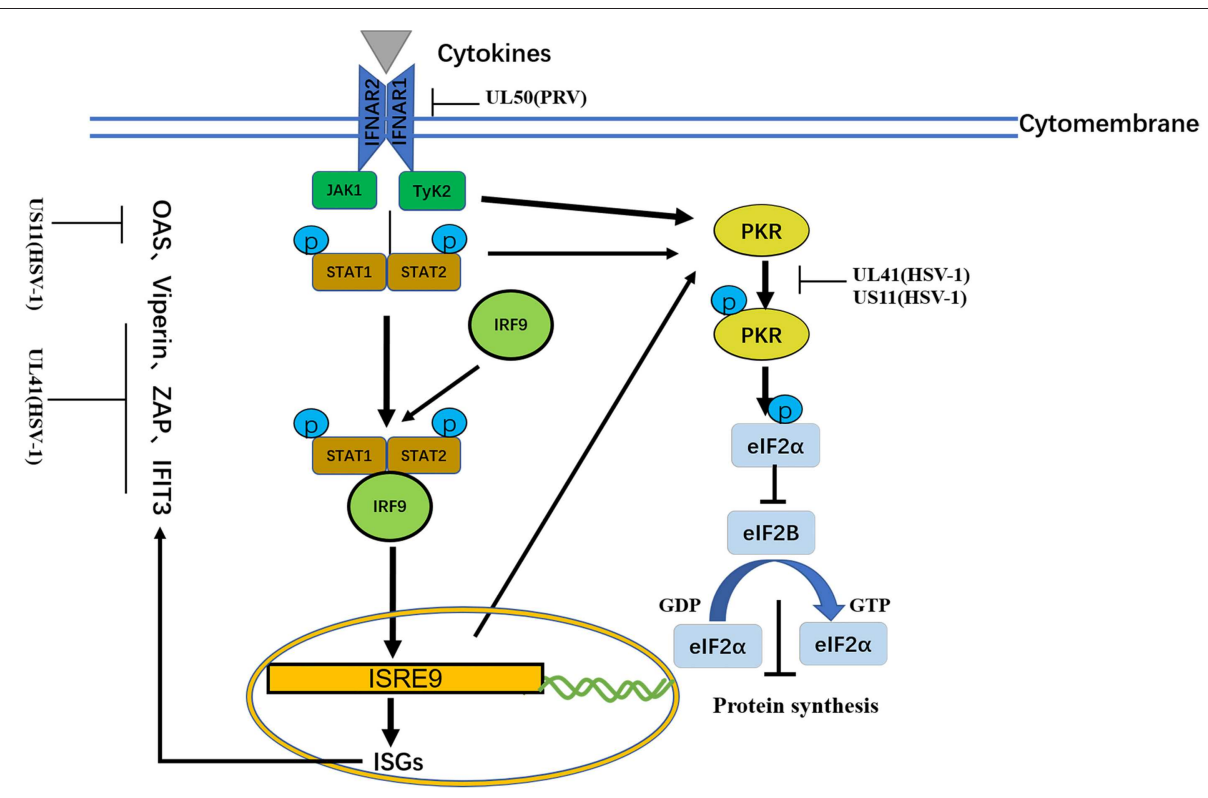

FIGURE 5 | A schematic diagram of the pathogen-derived molecules used to escape cytokine-sensing pathways in cells. In the basic transmission process of the JAK/STAT signaling pathway, the binding of cytokines to their receptors causes dimerization of the receptor molecules. The close proximity, of JAKs to the receptors enables their activation through interactive tyrosine phosphorylation. The immune evasion effect of the virus can be achieved through the degradation of IFNAR1 and ISG mRNA. 


\section{OAS}

Similar to PKR, OAS recognizes dsRNA. The three primary forms of OAS recognize dsRNA through positively charged channels in the molecule. Conformational changes in OAS after binding to dsRNA lead to the synthesis of $2^{\prime}, 5^{\prime}$-oligoadenylates (2-5As), which then activate latent RNase L, leading to the degradation of viruses and endogenous RNA and the inhibition of viral replication. OAS is essential for host defense and can be inhibited by pUS11 via its dsRNA binding domain, with pUS11 sequestering any available dsRNA produced during infection as the potential underlying mechanism (122).

\section{IFIT3}

The IFN-induced protein with tetratricopeptide repeats (IFIT) family includes IFIT1 (ISG56), IFIT2 (ISG54), IFIT3 (ISG60), and IFIT5 (ISG58), which are distributed on human chromosome. Recent studies have shown that IFIT proteins restrict viral replication by altering protein synthesis, binding viral RNA or interacting with structural or non-structural viral proteins to exert antiviral effects (128). Jiang showed for the first time that IFIT3 has little effect on the replication of HSV-1, because pUL41/VHS reduces the accumulation of IFIT3 mRNA and disrupts its antiviral activity (119).

\section{JAK/STAT Signaling Pathway}

During viral infection, IFNs exert their antiviral function by inducing antiviral proteins via the JAK/STAT pathway (129). Four JAKs and seven STATs have been identified in mammals. JAKs are tyrosine kinases of the Janus family, include JAK-1, JAK-2, JAK-3, and Tyk-2. The STATs include STAT-1, STAT-2, STAT-3, STAT-4, STAT-5a, STAT-5b, and STAT6. JAK-1, JAK2, Tyk-2, STAT-1, STAT-2, STAT-4, and STAT-5 are directly involved in IFN-mediated signaling transduction pathways. The JAK/STAT signaling pathway is a common pathway that includes many cytokine signaling molecules and plays extensive roles in cell proliferation, differentiation, apoptosis and inflammation. This pathway exerts its function by interacting with negative regulators in other signaling pathways and STAT-mediated covalent modifications. In the basic transmission process of the JAK/STAT signaling pathway, the binding of cytokines with their receptors induces receptor molecule dimerization. The proximity of JAKs to receptors then enables JAK activation through interactive tyrosine phosphorylation. Activated JAKs catalyze the tyrosine phosphorylation of receptors and form corresponding STAT docking sites, which enable STATs to bind to receptors through the $\mathrm{SH} 2$ domain and cooperate with JAKs. After phosphorylation, STATs form homodimers that divert into the nucleus, wherein they bind to the promoters of target genes to activate their transcription and expression (Figure 5 and Table 7).

\section{IFNAR1}

Because lacking intrinsic protein kinase domains, IFNAR1 and IFNAR2 rely on the 74 members of the JAK family for signal transduction (131). The results published by Zhang suggested that pUL50 has dUTPase activity. dUTPase catalyzes the hydrolysis of dUTP into dUMP and inorganic pyrophosphate, providing the dUMP precursor for dTTP biosynthesis and inhibiting IFN signaling. dUTPase also has the ability to suppress type I IFN signaling by promoting the lysosomal degradation of IFNAR1, thereby contributing to innate immune evasion (130) (Table 6).

\section{Cytokine Signaling Pathways}

Cytokines are small molecular proteins with extensive biological activity stimulated by immune cells (such as monocytes, macrophages, T cells, B cells, and natural killer (NK) cells) and some non-immune cells (endothelial cells, epidermal cells, and fibroblasts). Cytokines are produced by many kinds of cells induced by immunogens, mitogens or other stimulants and have many functions such as regulating innate and adaptive immunity, hematopoiesis, cell growth, and damaged tissue repair. Aside from IFNs, other cytokines can be classified into the following categories according to their function: ILs, TNF$\alpha$, TNF- $\beta$, colony-stimulating factors, chemokines, and growth factors (Table 8) (132).

\section{SOCS1 and SOCS3}

Suppressor of cytokine signaling 1 (SOCS1) and SOCS3 contain kinase inhibitory regions (KIRs) that can inhibit JAK signal transduction through the $\mathrm{SH} 2$ domain and interact with the phosphotyrosines of JAK and GP130, respectively (138). In addition to IFNs, PAMPs are effective inducers of SOCS1 and SOCS3. Because SOCS proteins negatively regulate cytokine signal transduction, many viruses induce the expression of SOCSs to aid in their survival (139). The SOCS family has eight members and suppresses various cytokine signaling pathways, including the IFN signaling pathway. In one study, the expression of eight SOCS family members during HSV-1 infection was analyzed by q RT-PCR, revealing that the tegument protein pUL13 could induce SOCS1 and SOCS3. However, no such induction was observed in UL13-deficient virus-infected cells, suggesting that the UL13 protein kinase was involved in the induction of the two genes (136).

\section{TNF- $\alpha$}

TNF- $\alpha$ is a cytokine with multipotent biological effects that are triggered by two types of TNF- $\alpha$ receptors on the cell surface (140). The TNF- $\alpha$ signaling transduction pathway primarily involves caspase family-mediated apoptosis and activation of the transcription factors NF- $\mathrm{BB}$ and JNK protein kinase mediated by TRAF (141). The expression of TNF- $\alpha$ has been observed to be increased in the spleens of mice infected with PRV UL41 mutant virus. TNF- $\alpha$ is considered to be an important cytokine in innate immune responses. In addition, PRV UL41 plays an important role in targeting host innate immune responses via its ribonuclease activity. Studies have suggested that pUL41 may contribute to the protection of organisms from viral damage mediated by TNF- $\alpha$ via degradation TNF- $\alpha$ mRNA (133).

\section{SLPI}

Secretory leukocyte protease inhibitor (SLPI), an antiinflammatory mediator of mucosal immunity, can inhibit both human immunodeficiency virus (HIV) and HSV in cell culture. Epidemiological studies have shown that high 
TABLE 7 | Immune evasion of tegument proteins through the JAK/ STAT signaling pathway.

\begin{tabular}{llll}
\hline Protein & Virus & Function & Reference \\
\hline UL50 & PRV & $\begin{array}{l}\text { Promotes the lysosomal } \\
\text { degradation of IFNAR1 }\end{array}$ & (130) \\
\hline
\end{tabular}

TABLE 8 | Immune evasion of tegument proteins through cytokine signaling.

\begin{tabular}{|c|c|c|c|}
\hline Protein & Virus & Function & References \\
\hline \multirow[t]{2}{*}{ UL49 (VP22) } & HSV-1 & $\begin{array}{l}\text { Interacts with AIM2 and prevents } \\
\text { its oligomerization }\end{array}$ & $(115)$ \\
\hline & & Inhibits OAS & \\
\hline UL41 & PRV & $\begin{array}{l}\text { Reduces the expression of } \\
\text { TNF- } \alpha\end{array}$ & $(133)$ \\
\hline UL41 & HSV-1 & $\begin{array}{l}\text { Suppresses cytokines such as } \\
\text { IL-1 } 1 \beta \text { and IL-18 }\end{array}$ & $(134)$ \\
\hline RL2 (ICP0)/RS1 (ICP4) & HSV & $\begin{array}{l}\text { Downregulates SLPI or activates } \\
\text { NF-кB }\end{array}$ & $(135)$ \\
\hline UL13 & HSV-1 & Induces SOCS1 and SOCS3 & $(136)$ \\
\hline US10 & DEV & $\begin{array}{l}\text { Downregulates the transcript } \\
\text { levels of IL-4, IL-6, and IL-10 }\end{array}$ & $(137)$ \\
\hline
\end{tabular}

concentrations of SLPI in mucosal secretions can inhibit HIV transmission. Whether the loss of SLPI caused by HSV allows the virus to evade the host's innate immune response is currently being studied, and the loss of SLPI may lead to an increased risk of HIV infection in the context of HSV infection (142). Reverse transcription PCR experiments have shown that SLPI is lost due to downregulating genes expression. The downregulation of SLPI is related to NF- $\mathrm{B}$ signaling pathway activation and inflammatory cytokine upregulation. Fakioglu showed that the ICP4- or ICP0-induced expression of immediate-early genes can downregulate SLPI or activate NF- $\kappa \mathrm{B}$ (135).

\section{ILs}

ILs are cytokines that are produced by and used in many types of cells. Currently, at least 38 ILs, named IL-1 to IL38, have been identified. These ILs have complex functions, forming networks and exhibiting complex overlaps, and playing important roles in the maturation, activation, proliferation, and immune regulation of immune cells. In addition, they also participate in various physiological and pathological reactions in organisms. For example, the proliferation, differentiation and functions of immune cells are regulated by a series of cytokines. According to their structure, cytokines can be divided into several protein families, such as the IL-1, IL-6, IL-10, TNF, and hematopoietic factor families (143). ILs can lead to local inflammation and cause sterilization and cell damage. Suzutani showed that a UL41-deleted strain of HSV-1 exhibited 20- and 5 -fold higher sensitivity to IFN- $\alpha$ and IFN- $\beta$ than the wild-type strain, respectively. These results indicate that one important role of HSV-1 pUL41/VHS in vivo is the evasion of non-specific host defense mechanisms during primary infection by suppressing cytokines such as IL-1 $\beta$ and IL-18 (134). A study by Ma (137) showed that DEV pUS10, which plays an important role in viral replication, could upregulate the transcription of IL-4, IL-6, and IL-10 in US10-deleted DEV-infected duck embryonic fibroblasts (DEFs) at all assayed time points (Table 7).

\section{NK Cells}

Functional NK cells are essential for limiting herpesvirus transmission and disease symptoms. There are many types of receptors on the NK cell surface, and their functions can be divided into two categories: activation and inhibition of the proliferation system. By recognizing specific ligands, NK cells can sense changes of target cells surface properties. To prevent clearance from cytotoxic $\mathrm{T}$ lymphocytes, some viruses actively reduce the level of MHC class I (MHC-I), an important ligand of the KIR family on the cell surface inhibiting NK cell receptors (144). To benefit their survival, viruses can encode MHC-I-like proteins that activate KIR receptors and proteins that inhibit the exposure of NK cell receptor ligands.

CD300a, also known as IRP60, is a highly conserved inhibitory NK cell receptor that does not bind to MHC-I. $\mathrm{CD} 300 \mathrm{a}$ is a $60 \mathrm{kDa}$ protein belonging to the immunoglobulin (Ig) superfamily that is characterized by a single V-type Ig-like domain in its extracellular domain and several tyrosine-based immunoreceptor inhibition motifs (ITIMs) in its cytoplasmic domain (145). CD300a can identify aminophospholipids exposed on the cell surface, especially phosphatidylserine (PS) and phosphatidylethanolamine (PE), which can inhibit the cytolysis of NK cells by binding to ligands (146). CD300a inhibitory receptors and their lipid ligands have been specifically reported on mammals, birds and fish (147). To date, no descriptions of the NK cell evasion strategy involving CD300a have been reported. A study by Grauwet firstly indicated that the pUS3 protein kinase of the alphaherpesvirus PRV can trigger the inhibitory $\mathrm{NK}$ cell receptor CD300a binding to the surface of infected cells, thereby increasing the CD300a-mediated protection of the infected cells. In addition, the binding of pUS3 to $\mathrm{CD} 300 \mathrm{a}$ is associated with the aminophospholipid ligand of CD300a and the IP21 activating kinase (148), thus representing a novel alphaherpesvirus strategy for escaping NK cells.

\section{Other Innate Immune Responses The DDR Response}

The cellular DDR pathway monitors damage to genomic DNA. DNA-PK, ataxia telangiectasia mutated (ATM) kinase, and ATM- and Rad3-related (ATR) kinase are the primary signaling pathway mediators that initiate the DDR (48). Recently, cellular DNA repair machinery was demonstrated to recognize viral genetic material (149). The DDR plays an important role in viral infection, participating in the activation of many components of the ATM-dependent signaling pathway and inhibiting the DNA PKC- and ATR-dependent arms (150). Lilley and colleagues showed that RNF8 and RNF168, important mediators of ATM-dependent signaling pathways, are targeted for proteasome-mediated degradation by ICP0 (151). 


\section{ER Stress}

The endoplasmic reticulum (ER) is a cytoplasmic eukaryotic organelle that has numerous functions, taking part in the transport of cellular materials, the provision of increased surface areas for cellular reactions, and the production of proteins, steroids and lipids (152). Mis- and unfolded proteins that can cause stress in the ER accumulate during viral replication and trigger the unfolded protein response (UPR) (153). The IRE1/XBP1 pathway is the most conserved component of the UPR branch in eukaryotic cells (154). IRE1 is a dual-activity enzyme that contains a serine-threonine kinase domain and a ribonuclease domain (155). Upon activation, IRE1 undergoes dimerization and transphosphorylation, which facilitates the removal of a 26-nucleotide (NT) intron from the XBP1 gene to form a spliced XBP1, which translated into a transcription factor. In the nucleus, XBP1 induces the expression of the genes that enhance the folding ability of ER proteins and functions in phospholipid biosynthesis and ER-associated protein degradation (ERAD) (156). During HSV-1 infection, the molecular mechanism by which the IRE1/XBP1 branch of the UPR is repressed remains unclear. Zhang and colleagues showed that the HSV-1 tegument protein pUL41, which has endoribonuclease activity, degrades XBP1 mRNA to inhibit its expression (157). These findings reveal a novel mechanism by which HSV-1 modulates the IRE1/XBP1 branch of the UPR. Interestingly, the HSV-1 ICP0 promoter can react to ER stress. Burnett and colleagues found that ICP0 can activate itself independently during HSV-1 infection, suggesting that HSV-1 regulates the ER stress response through ICP0 (153).

\section{CONCLUSION}

Over millions of years of coevolution between host and viruses, host species have developed a highly complex set of physiological immune mechanisms to block and eliminate viral infection. However, for every host immune response step, viruses have

\section{REFERENCES}

1. Owen DJ, Crump CM, Graham SC. Tegument assembly and secondary envelopment of alphaherpesviruses. Viruses. (2015) 7:5084-114. doi: 10.3390/v7092861

2. Wu Y, Cheng A, Wang M, Zhu D, Jia R, Chen S, et al. Comparative genomic analysis of Duck Enteritis Virus strains. J Virol. (2012) 86:13841-2. doi: 10.1128/JVI.01517-12

3. You Y, Cheng A, Wang M, Jia R, Sun K, Yang Q, et al. The suppression of apoptosis by $\alpha$-herpesvirus. Cell Death Dis.(2017) 8:e2749. doi: $10.1038 /$ cddis.2017.139

4. Zeev-Ben-Mordehai T, Hagen C, Grünewald K. A cool hybrid approach to the herpesvirus "life" cycle. Curr Opin Virol. (2014) 5:42-9. doi: 10.1016/j.coviro.2014.01.008

5. Johnson DC, Baines JD. Herpesviruses remodel host membranes for virus egress. Nat Rev Microbiol. (2011) 9:382-94. doi: 10.1038/nrmicro2559

6. Mettenleiter TC, Klupp BG, Granzow H. Herpesvirus assembly: an update. Virus Res. (2009) 143:222-34. doi: 10.1016/j.virusres.2009.03.018

7. Everett RD. The spatial organization of DNA virus genomes in the nucleus. PLoS Pathog. (2013) 9:e1003386. doi: 10.1371/journal.ppat.1003386 developed corresponding immune escape mechanisms to ensure their own survival. Successful immune escape is a primary factor underlying chronic herpesvirus infection. In recent years, substantial progress has been made in understanding the variety of cytoplasmic DNA sensors that enable resistance to the immune response. Tegument proteins play important role in alphaherpesvirus innate immune evasion. However, despite the mapping of antiviral defense signaling pathways between tegument proteins and host, a functional understanding of how tegument proteins work together to interfere with the innate immune system remains elusive. Further studies on the mechanisms of tegument proteins, capsid proteins, and glycoproteins will be helpful in the search for antiviral targets and development of antiviral drugs.

\section{AUTHOR CONTRIBUTIONS}

LY wrote the manuscript and constructed the figures. AC and MW contributed ideas for the review. QY, YWu, RJ, ML, DZ, SC, SZ, XZ, JH, YWa, ZX, ZC, LZhu, QL, YL, YY, LZha, BT, LP, MR, and $\mathrm{XC}$ edited and revised the manuscript.

\section{FUNDING}

This work was supported by the National Key Research and Development Program of China (2017YFD0500800), the China Agricultural Research System (CARS-4217), and the Sichuan Veterinary Medicine and Drug Innovation Group of the China Agricultural Research System (CARS-SVDIP).

\section{ACKNOWLEDGMENTS}

We apologize to the authors of articles reporting relevant research that were not cited in this manuscript due to limited space.
8. Benetti L, Roizman B. Herpes simplex virus protein kinase US3 activates and functionally overlaps protein kinase A to block apoptosis. Proc Natl Acad Sci USA. (2004) 101:9411-6. doi: 10.1073/pnas.0403160101

9. Nicoll MP, Proença JT, Efstathiou S. The molecular basis of herpes simplex virus latency. FEMS Microbiol Rev. (2012) 36:684-705. doi: 10.1111/j.1574-6976.2011.00320.x

10. Leib DA, Coen DM, Bogard CL, Hicks KA, Yager DR, Knipe DM, et al. Immediate-early regulatory gene mutants define different stages in the establishment and reactivation of herpes simplex virus latency. J Virol. (1989) 63:759-68.

11. Wang Q, Zhou C, Johnson KE, Colgrove RC, Coen DM, Knipe DM. Herpesviral latency-associated transcript gene promotes assembly of heterochromatin on viral lytic-gene promoters in latent infection. Proc Natl Acad Sci USA. (2005) 102:16055-9. doi: 10.1073/pnas. 0505850102

12. Roizman BJ. The checkpoints of viral gene expression in productive and latent infection: the role of the HDAC/CoREST/LSD1/REST repressor complex. Virol. (2011) 85:7474-82. doi: 10.1128/JVI.00180-11

13. Ju YK, Angelo M, Moses VC, Ian M, Angus CW. Transient reversal of episome silencing precedes VP16 dependent transcription during 
reactivation of latent HSV-1 in neurons. PLoS Pathogen. (2012) 8:e1002540. doi: 10.1371/journal.ppat.1002540

14. Loret S, Guay G, Lippé R. Comprehensive characterization of extracellular herpes simplex virus type 1 virions. J Virol. (2008) 82:8605-18. doi: 10.1128/JVI.00904-08

15. Karasneh GA, Shukla D. Herpes simplex virus infects most cell types in vitro: clues to its success. Virol J. (2011) 8:481. doi: 10.1186/1743-422X-8-481

16. Zhou H, Chen H, Jakana J, Rixon FJ, Chiu W. Visualization of tegumentcapsid interactions and DNA in intact herpes simplex virus type 1 virions. $J$ Virol. (1999) 73:3210-8.

17. Dai X, Gong D, Wu T, Sun R, Zhou ZH. Organization of capsid-associated tegument components in Kaposi's sarcoma-associated herpesvirus. J Virol. (2014) 88:12694-702. doi: 10.1128/JVI.01509-14

18. Grünewald K, Desai P, Winkler DC, Heymann JB, Belnap DM, Baumeister W, et al. Three-dimensional structure of herpes simplex virus from cryo-electron tomography. Science. (2003) 302:1396-8. doi: $10.1126 /$ science. 1090284

19. Diefenbach RJ. Conserved tegument protein complexes: essential components in the assembly of herpesviruses. Virus Res. (2015) 201:308-17. doi: 10.1016/j.virusres.2015. 09.007

20. Xu H, Su C, Pearson A, Mody CH, Zheng C. Herpes simplex virus 1 UL24 abrogates the DNA sensing signal pathway by inhibiting NF-кB activation. $J$ Virol. (2017) 91:E00025-17. doi: 10.1128/JVI.00025-17

21. Su C, Zhan G, Zheng C. Evasion of host antiviral innate immunity by HSV-1, an update. Virol J. (2016) 13:38. doi: 10.1186/s12985-016-0495-5

22. Frazao JB, Errante PR, Condino-Neto A. Toll-like receptors' pathway disturbances are associated with increased susceptibility to infections in humans. Arch Immunol Ther Exp (Warsz). (2013) 61:427-43. doi: 10.1007/s00005-013-0243-0

23. Reuven EM, Fink A, Shai Y. Regulation of innate immune responses by transmembrane interactions: lessons from the TLR family. Biochim Biophys Acta. (2014) 1838:1586-93. doi: 10.1016/j.bbamem.2014.01.020

24. Chen S, Wu Z, Wang MS, Cheng AC. Innate immune evasion mediated by flaviviridae non-structural proteins. Viruses. (2017) 9:291. doi: $10.3390 / \mathrm{v} 9100291$

25. Ma Y, He B. Recognition of herpes simplex viruses: toll-like receptors and beyond. J Mol Biol. (2014) 426:1133-47. doi: 10.1016/j.jmb.2013.11.012

26. Unterholzner L. The interferon response to intracellular DNA: why so many receptors? Immunobiology. (2015) 218:1312-21. doi: 10.1016/j.imbio.2013.07.007

27. Gao P, Ascano M, Zillinger T, Wang W, Dai P, Serganov AA, et al. Structure-function analysis of STING activation by $\mathrm{c}\left[\mathrm{G}\left(2^{\prime}, 5^{\prime}\right) \mathrm{pA}\left(3^{\prime \prime}, 5^{\prime \prime}\right) \mathrm{p}\right]$ and targeting by antiviral DMXAA. Cell. (2013) 154:748-62. doi: 10.1016/j.cell.2013.07.023

28. Hornung V, Ellegast J, Kim S, Brzozka K, Jung A, Kato H, et al. 5' Triphosphate RNA is the ligand for RIG-I. Science. (2006) 314:994-7. doi: $10.1126 /$ science. 1132505

29. Ablasser A, Bauernfeind F, Hartmann G, Latz E, Fitzgerald KA, Hornung V. RIG-I-dependent sensing of poly(dA:dT) through the induction of an RNA polymerase III-transcribed RNA intermediate. Nat Immunol. (2009) 10:1065-72. doi: 10.1038/ni.1779

30. Chiu YH, Macmillan JB, Chen ZJ. RNA polymerase III detects cytosolic DNA and induces type I interferons through the RIG-I pathway. Cell. (2009) 138:576-91. doi: 10.1016/j.cell.2009.06.015

31. Casrouge A, Zhang SY, Eidenschenk C, Jouanguy E, Puel A, Yang K, et al. Herpes simplex virus encephalitis in human UNC-93B deficiency. Science. (2006) 314:308-12. doi: 10.1126/science.1128346

32. Dupuis S, Jouanguy E, Al-Hajjar S, Fieschi C, Al-Mohsen IZ, AlJumaah S, et al. Impaired response to interferon-alpha/beta and lethal viral disease in human STAT1 deficiency. Nat Genet. (2003) 33:388-91. doi: 10.1038/ng1097

33. Lim HK, Seppänen M, Hautala T, Ciancanelli MJ, Itan Y, Lafaille FG, et al. TLR3 deficiency in herpes simplex encephalitis: high allelic heterogeneity and recurrence risk. Neurology. (2014) 83:1888-97. doi: 10.1212/WNL.0000000000000999

34. Zhang SY, Jouanguy E, Ugolini S, Smahi A, Elain G, Romero P, et al. TLR3 deficiency in patients with herpes simplex encephalitis. Science. (2007) 317:1522-7. doi: $10.1126 /$ science. 1139522
35. Leib DA, Harrison TE, Laslo KM, Machalek MA, Moorman NJ, Virgin HW. Interferons regulate the phenotype of wild-type and mutant herpes simplex viruses in vivo. J Exp Med. (1999) 189:663-72. doi: 10.1084/jem.189.4.663

36. Austin BA, James C, Silverman RH, Carr DJ. Critical role for the oligoadenylate synthetase/RNase L pathway in response to IFN-beta during acute ocular herpes simplex virus type 1 infection. J Immunol. (2005) 175:1100-6. doi: 10.4049/jimmunol.175.2.1100

37. Lenschow DJ, Lai C, Frias-Staheli N, Giannakopoulos NV, Lutz A, Wolff T, et al. IFN-stimulated gene 15 functions as a critical antiviral molecule against influenza, herpes, and Sindbis viruses. Proc Natl Acad Sci USA. (2007) 104:1371-6. doi: 10.1073/pnas.0607038104

38. Ogunjimi B, Zhang SY, Sorensen KB, Skipper KA, CarterTimofte M, Kerner $\mathrm{G}$, et al. Inborn errors in RNA polymerase III underlie severe varicella zoster virus infections. J Clin Invest. (2017) 127:3543-56. doi: 10.1172/JCI92280

39. Carter-Timofte ME, Hansen AF, Christiansen M, Paludan SR, Mogensen TH. Mutations in RNA Polymerase III genes and defective DNA sensing in adults with varicella-zoster virus CNS infection. Genes Immun. (2018) 20:214-23. doi: 10.1038/s41435-018-0027-y

40. Randall RE, Goodbourn S. Interferons and viruses: an interplay between induction, signalling, antiviral responses and virus countermeasures. J Gen Virol. (2004) 89:1-47. doi: 10.1099/vir.0.83391-0

41. Takeuchi O, Akira S. Innate immunity to virus infection. Immunol Rev. (2009) 227:75-86. doi: 10.1111/j.1600-065X.2008.00737.x

42. Chatzinikolaou G, Karakasilioti I, Garinis GA. DNA damage and innate immunity: links and trade-offs. Trends Immunol. (2014) 35:429-35. doi: $10.1016 /$ j.it.2014.06.003

43. Luftig MA. Viruses and the DNA damage response: activation and antagonism. Ann Rev Virol. (2014) 1:605-25. doi: 10.1146/annurev-virology-031413-085548

44. Dong X, Levine B. Autophagy and viruses: adversaries or allies? J Innate Immun. (2013) 5:480-93. doi: 10.1159/000346388

45. Onomoto K, Yoneyama M, Fung G, Kato H, Fujita T. Antiviral innate immunity and stress granule responses. Trends Immunol. (2014) 35:420-8. doi: 10.1016/j.it.2014.07.006

46. Brownlie R, Allan B. Avian toll-like receptors. Cell Tissue Res. (2011) 343:121-30. doi: 10.1007/s00441-010-1026-0

47. Lester SN, Li K. Toll-like receptors in antiviral innate immunity. J Mol Biol. (2013) 426:1246-64. doi: 10.1016/j.jmb.2013.11.024

48. Lanfranca MP, Mostafa HH, Davido DJ. HSV-1 ICP0: An E3 ubiquitin ligase that counteracts host intrinsic and innate immunity. Cells. (2014) 3:438-54. doi: 10.3390/cells3020438

49. van Lint AL, Murawski MR, Goodbody RE, Severa M, Fitzgerald KA, Finberg RW, et al. Herpes simplex virus immediate-early ICP0 protein inhibits Tolllike receptor 2-dependent inflammatory responses and NF-kappaB signaling. J Virol. (2010) 84:10802-11. doi: 10.1128/JVI.00063-10

50. Peri P, Mattila RK, Kantola H, Broberg E, Karttunen HS, Waris M. Herpes simplex virus type 1 Us3 gene deletion influences toll-like receptor responses in cultured monocytic cells. Virol J. (2008) 5:140. doi: 10.1186/1743-422X-5-140

51. Sen J, Liu X, Roller R, Knipe DM. Herpes simplex virus US3 tegument protein inhibits Toll-like receptor 2 signaling at or before TRAF6 ubiquitination. Virology. (2013) 439:65-73. doi: 10.1016/j.virol.2013.01.026

52. Yao XD, Rosenthal KL. Herpes simplex virus type 2 virion host shutoff protein suppresses innate dsRNA antiviral pathways in human vaginal epithelial cells. J Gen Virol. (2011) 92(Pt 9):1981-93. doi: 10.1099/vir.0.030296-0

53. Chen J, Panagiotidis C, Silverstein S. Multimerization of ICP0, a herpes simplex virus immediate-early protein. J Virol. (1992) 66:5598-602.

54. Sacks WR, Schaffer PA. Deletion mutants in the gene encoding the herpes simplex virus type 1 immediate-early protein ICP0 exhibit impaired growth in cell culture. J Virol. (1987) 61:829-39.

55. Vanni E, Gatherer D, Tong L, Everett RD, Boutell C. Functional characterization of residues required for the herpes simplex virus 1 E3 ubiquitin ligase ICP0 to interact with the cellular E2 ubiquitinconjugating enzyme UBE2D1 (UbcH5a). J Virol. (2012) 86:6323-33. doi: 10.1128/JVI.07210-11

56. Hagglund R, Van SC, Lopez P, Roizman B. Herpes simplex virus 1-infected cell protein 0 contains two E3 ubiquitin ligase sites specific for different E2 
ubiquitin-conjugating enzymes. Proc Natl Acad Sci USA. (2002) 99:631-6. doi: 10.1073/pnas.022531599

57. Boutell C, Sadis S, Everett RD. Herpes simplex virus type 1 immediate-early protein ICP0 and is isolated RING finger domain act as ubiquitin E3 ligases in vitro. J Virol. (2002) 76:841-50. doi: 10.1128/JVI.76.2.841-850.2002

58. Barbalat R, Lau L, Locksley RM, Barton GM. Toll-like receptor 2 on inflammatory monocytes induces type I interferon in response to viral but not bacterial ligands. Nat Immunol. (2009) 10:1200-7. doi: 10.1038/ni.1792

59. Zhang SY, Jouanguy E, Sancho-Shimizu V, von Bernuth H, Yang K, Abel $\mathrm{L}$, et al. Human Toll-like receptor-dependent induction of interferons in protective immunity toviruses. Immunol Rev. (2007) 220:225-36. doi: 10.1111/j.1600-065X.2007.00564.x

60. Fitzgerald KA, Palsson-McDermott EM, Bowie AG, Jefferies CA, Mansell AS, Brady G, et al. Mal (MyD88-adapter-like) is required for Toll-like receptor-4 signal transduction. Nature. (2001) 413:78-83. doi: 10.1038/35092578

61. Oliveira-Nascimento L, Massari P, Wetzler LM. The role of TLR2 in infection and immunity. Front Immunol. (2012) 3:79. doi: 10.3389/fimmu.2012.00079

62. Rathinam VA, Fitzgerald KA. Innate immune sensing of DNA viruses. Virology. (2011) 411:153-62. doi: 10.1016/j.virol.2011.02.003

63. Frame MC, Purves FC, McGeoch DJ, Marsden HS, Leader DP. Identification of the herpes simplex virus protein kinase as the product of viral gene US3. J Gen Virol. (1987) 68(Part 10):2699-704. doi: 10.1099/0022-1317-68-10-2699

64. Matsumiya T, Stafforini DM. Function and regulation of retinoic acid-inducible gene-I. Crit Rev Immunol. (2010) 30:489-513. doi: 10.1615/CritRevImmunol.v30.i6.10

65. Guo H, Zhang X, Jia R. Toll-like receptors and RIG-I-like receptors play important roles in resisting flavivirus. J Immunol Res. (2018) 2018:6106582. doi: 10.1155/2018/6106582

66. Chen S, Cheng A, Wang M. Innate sensing of viruses by pattern recognition receptors in birds. Vet Res. (2013) 44:82. doi: 10.1186/1297-9716-44-82

67. Zhao J, Zeng Y, Xu S, Chen J, Shen G, Yu C, et al. A viral deamidase targets the helicase domain of RIG-I to block RNA-induced activation. Cell Host Microbe. (2016) 20:770-84. doi: 10.1016/j.chom.2016.10.011

68. Kato H, Takeuchi O, Sato S, Yoneyama M, Yamamoto M, Matsui K, et al. Differential roles of MDA5 and RIG-I helicases in the recognition of RNA viruses. Nature. (2006) 441:101-5. doi: 10.1038/nature04734

69. Wang S, Wang K, Lin R, Zheng C. Herpes simplex virus 1 serine/threonine kinase US3 hyperphosphorylates IRF3 and inhibits beta interferon production. J Virol. (2013) 87:12814-27. doi: 10.1128/JVI.02355-13

70. Xing J, Wang S, Lin R, Mossman KL, Zheng C. Herpes simplex virus 1 tegument protein US11 downmodulates the RLR signaling pathway via direct interaction with RIG-I and MDA-5. J Virol. (2012) 86:3528-40. doi: 10.1128/JVI.06713-11

71. Wang S, Wang K, Li J, Zheng CF. Herpes simplex virus 1 ubiquitin-specific protease UL36 inhibits beta interferon production by deubiquitinating TRAF3. J Virol. (2013) 87:11851-60. doi: 10.1128/JVI.01211-13

72. Verpooten D, Ma Y, Hou S, Yan Z, He B. Control of TANK-binding kinase 1-mediated signaling by the gamma (1) 34.5 protein of herpes simplex virus 1. J Biol Chem. (2009) 284:1097-105. doi: 10.1074/jbc.M805905200

73. Manivanh R, Mehrbach J, Knipe DM, Leib DA. Role of herpes simplex virus $1 \gamma 34.5$ in the regulation of IRF3 signaling. J Virol. (2017) 91:e01156-17. doi: 10.1128/JVI.01156-17

74. You H, Zheng S, Huang Z, Lin Y, Shen Q, Zheng C. Herpes simplex virus 1 tegument protein UL46 inhibits TANK-binding kinase 1-mediated signaling. MBio. (2019) 10:e00919. doi: 10.1128/mBio.00919-19

75. Zheng C, Su C. Herpes simplex virus 1 infection dampens the immediate early antiviral innate immunity signaling from peroxisomes by tegument protein VP16. Virol J. (2017) 14:35. doi: 10.1186/s12985-017-0709-5

76. Zhu H, Zheng C, Xing J, Wang S, Li S, Lin R. Varicella-zoster virus immediate-early protein ORF61 abrogates the IRF3-mediated innate immune response through degradation of activated IRF3. J Virol. (2011) 85:11079-89. doi: 10.1128/JVI.05098-11

77. Vandevenne P, Lebrun M, El MN, Ote I, Di VE, Habraken Y, et al. The varicella-zoster virus ORF47 kinase interferes with host innate immune response by inhibiting the activation of IRF3. PLoS ONE. (2011) 6:e16870. doi: 10.1371/journal.pone.0016870

78. Sen N, Sommer M, Che X, White K, Ruyechan WT, Arvin AM. Varicellazoster virus immediate-early protein 62 blocks interferon regulatory factor
3 (IRF3) phosphorylation at key serine residues: a novel mechanism of IRF3 inhibition among herpesviruses. J Virol. (2010) 84:9240-53. doi: 10.1128/JVI.01147-10

79. Guan $\mathrm{X}$, Zhang $\mathrm{M}, \mathrm{Fu}$ M, Luo S, Hu Q. Herpes simplex virus type 2 immediate early protein ICP27 inhibits IFN- $\beta$ production in mucosal epithelial cells by antagonizing IRF3 activation. Front Immunol. (2019) 10:290. doi: 10.3389/fimmu.2019.00290

80. Kawai T, Takahashi K, Sato S, Coban C, Kumar H, Kato H. IPS-1, an adaptor triggering RIG-I- and Mda5-mediated type I interferon induction. Nat Immunol. (2005) 6:981-8. doi: 10.1038/ni1243

81. Hou F, Sun L, Zheng H, Skaug B, Jiang QX, Chen ZJ. MAVS forms functional prion-like aggregates to activate and propagate antiviral innate immune response. Cell. (2011) 146:448-61. doi: 10.1016/j.cell.2011. 06.041

82. Mossman KL, Sherburne R, Lavery C, Duncan J, Smiley JR. Evidence that herpes simplex virus VP16 is required for viral egress downstream of the initial envelopment event. J Virol. (2000) 74:6287-99. doi: 10.1128/JVI.74.14.6287-6299.2000

83. Hacker H, Redecke V, Blagoev B, Kratchmarova I, Hsu LC, Wang GG, et al. Specificity in Toll-like receptor signalling through distinct effector functions of TRAF3 and TRAF6. Nature. (2006) 439:204-7. doi: 10.1038/nature 04369

84. Tu D, Zhu Z, Zhou AY, Yun CH, Lee KE, Toms AV, et al. Structure and ubiquitination-dependent activation of TANK-binding kinase 1. Cell Rep. (2013) 3:747-58. doi: 10.1016/j.celrep.2013.01.033

85. Chou J, Roizman B. The herpes simplex virus 1 gene for ICP34.5, which maps in inverted repeats, is conserved in several limited-passage isolates but not in strain 17syn+. J Virol. (1990) 64:1014-20.

86. Takeuchi O. IRF3: a molecular switch in pathogen responses. Nat Immunol. (2012) 13:634-5. doi: 10.1038/ni.2346

87. Piroozmand A, Koyama AH, Shimada Y, Fujita M, Arakawa T, Adachi A. Role of Us3 gene of herpes simplex virus type 1 for resistance to interferon. Int J Mol Med. (2004) 14:641-5. doi: 10.3892/ijmm.14.4.641

88. Balachandran S, Beg AA. Defining emerging roles for NF-kB in antivirus responses: revisiting the interferon $\beta$ enhanceosome paradigm. PLoS Pathog. (2011) 7:e1002165. doi: 10.1371/journal.ppat.1002165

89. Hayden MS, Ghosh S. Signaling to NF-kappaB. Genes (Basel). (2004) 18:2195-224. doi: 10.1101/gad.1228704

90. Deng L, Zeng Q, Wang M, Cheng A, Jia R, Chen S, et al. Suppression of NF-КB activity: a viral immune evasion mechanism. Viruses. (2018) 10:E409. doi: $10.3390 / \mathrm{v} 10080409$

91. Xing J, Ni L, Wang S, Wang KZ, Lin RT, Zheng CF. Herpes simplex virus 1-encoded tegument protein VP16 abrogates the production of beta interferon (ifn) by inhibiting NF-KB activation and blocking IFN regulatory factor 3 to recruit its coactivator CBP. J Virol. (2013) 87:9788-801. doi: 10.1128/JVI.01440-13

92. Whitmer T, Malouli D, Uebelhoer LS, DeFilippis VR, Früh K, Verweij MC. The ORF61 protein encoded by simian varicella virus and varicella-zoster virus inhibits NF-кB signaling by interfering with ІкB $\alpha$ degradation. $J$ Virol. (2015) 89:8687-700. doi: 10.1128/JVI.01149-15

93. Sloan E, Henriquez R, Kinchington PR, Slobedman B, Abendroth A. Varicella-zoster virus inhibition of the NF- $\mathrm{kB}$ pathway during infection of human dendritic cells: role for open reading frame 61 as a modulator of NF-кB activity. J Virol. (2012) 86:1193-202. doi: 10.1128/JVI.06400-11

94. Zhang J, Wang K, Wang S, Zheng C. Herpes simplex virus 1 E3 ubiquitin ligase ICP0 protein inhibits tumor necrosis factor alpha-induced NF-kappaB activation by interacting with p65/RelA and p50/NF-kappaB1. J Virol. (2013) 87:12935-48. doi: 10.1128/JVI.01952-13

95. Diao L, Zhang B, Fan J, Gao X, Sun S, Yang K, et al. Herpes virus proteins ICP0 and BICP0 can activate NF-kappa B by catalyzing IkappaBalpha ubiquitination. Cell Signal. (2005) 17:217-29. doi: 10.1016/j.cellsig.2004.07.003

96. La Frazia S, Amici C, Santoro MG. Antiviral activity of proteasome inhibitors in herpes simplex virus-1 infection: Role of nuclear factor-kappaB. Antivir Ther. (2006) 11:995-1004.

97. Wang K, Ni L, Wang S, Zheng C. Herpes simplex virus 1 protein kinase US3 hyperphosphorylates p65/RelA and dampens NF-B activation. J Virol. (2014) 88:7941-51. doi: 10.1128/JVI.03394-13 
98. Hanks SK, Quinn AM, Hunter T. The protein kinase family: conserved features and deduced phylogeny of the catalytic domains. Science. (1988) 241:42-52. doi: 10.1126/science.3291115

99. Orzalli MH, DeLuca NA, Knipe DM. Nuclear IFI16 induction of IRF3 signaling during herpesviral infection and degradation of IFI16 by the viral ICP0 protein. Proc Natl Acad Sci USA. (2012) 109:E3008-17. doi: $10.1073 /$ pnas. 1211302109

100. Deschamps T, Kalamvoki M. Impaired STING pathway in human osteosarcoma U2OS cells contributes to the growth of ICP0null mutant herpes simplex virus. J Virol. (2017) 91:e00006-17. doi: 10.1128/JVI.00006-17

101. Taylor KE, Chew MV, Ashkar AA, Mossman KL. Novel roles of cytoplasmic ICP0: proteasome-independent functions of the RING finger are required to block interferon-stimulated gene production but not to promote viral replication. J Virol. (2014) 88:8091-101. doi: 10.1128/JVI.00944-14

102. Paladino P, Collins SE, Mossman KL. Cellular localization of the herpes simplex virus ICP0 protein dictates its ability to block IRF3mediated innate immune responses. PLOS ONE. (2010) 5:e10428. doi: 10.1371/journal.pone.0010428

103. Huang J, You H, Su C, Li Y, Chen S, Zheng C. Herpes simplex virus 1 tegument protein VP22 abrogates cGAS/STING-mediated antiviral innate immunity. J Virol. (2018) 92:e00841-18. doi: 10.1128/JVI. 00841-18

104. Deschamps T, Kalamvoki M. Evasion of the STING DNA-sensing pathway by VP11/12 of herpes simplex virus 1. J Virol. (2017) 91:e00535-17. doi: 10.1128/JVI.00535-17

105. Zhang J, Zhao J, Xu S, Li J, He S, Zeng Y, et al. Species-specific deamidation of cGAS by herpes simplex virus UL37 protein facilitates viral replication. Cell Host Microbe. (2018) 24:234-48. doi: 10.1016/j.chom.2018. 07.004

106. Christensen MH, Jensen SB, Miettinen JJ, Luecke S, Prabakaran T, Reinert LS. HSV-1 ICP27 targets the TBK1-activated STING signalsome to inhibit virus-induced type I IFN expression. EMBO J. (2016) 35:1385-99. doi: 10.15252/embj.201593458

107. Zhang X, Shi H, Wu J, Zhang X, Sun L, Chen C, et al. Cyclic GMPAMP containing mixed phosphodiester linkages is an endogenous high-affinity ligand for STING. Mol Cell. (2013) 51:226-35. doi: 10.1016/j.molcel.2013.05.022

108. Ishikawa H, Barber GN. STING is an endoplasmic reticulum adaptor that 530 facilitates innate immune signalling. Nature. (2008) 455:674-8. doi: $10.1038 /$ nature 07317

109. Unterholzner L, Keating SE, Baran M, Horan KA, Jensen SB, Sharma S, et al. IFI16 is an innate immune sensor for intracellular DNA. Nat Immunol. (2010) 11:997-1004. doi: 10.1038/ni.1932

110. Soby S, Laursen RR, Ostergaard L, Melchjorsen J. HSV-1-induced chemokine expression via IFI16-dependent and IFI16-independent pathways in human monocyte-derived macrophages. Herpesviridae. (2012) 3:6. doi: 10.1186/2042-4280-3-6

111. Johnson KE, Chikoti L, Chandran B. Herpes simplex virus 1 infection induces activation and subsequent inhibition of the IFI16 and NLRP3 inflammasomes. J Virol. (2013) 87:5005-18. doi: 10.1128/JVI.00082-13

112. Veeranki S, Choubey D. Interferon-inducible p200-family protein IFI16, an innate immune sensor for cytosolic and nuclear double-stranded DNA: regulation of subcellular localization. Mol Immunol. (2012) 49:56771. doi: 10.1016/j.molimm.2011.11.004

113. Delphine CL, Gail A, Elizabeth S, Anne O, Roger DE. The viral ubiquitin ligase ICP0 is neither sufficient nor necessary for degradation of the cellular DNA sensor IFI16 during herpes simplex virus 1 infection. J Virol. (2013) 87:13422-32. doi: 10.1128/JVI.02474-13

114. Wu J, Chen $\mathrm{ZJ}$. Innate immune sensing and signaling of cytosolic nucleic acids. Annu Rev Immunol. (2014) 32:461-88. doi: 10.1146/annurev-immunol-032713-120156

115. Maruzuru Y, Ichinohe T, Sato R, Miyake K, Okano T, Suzuki T, et al. Herpes simplex virus 1 VP22 inhibits AIM2-dependent inflammasome activation to Enable efficient viral replication. Cell Host Microbe. (2018) 23:254-65. doi: 10.1016/j.chom.2017.12.014

116. Sarkar SN, Sen GC. Novel functions of proteins encoded by viral stress-inducible genes. Pharmacol Ther. (2004) 103:245-59. doi: 10.1016/j.pharmthera.2004.07.007
117. Shen G, Wang K, Wang S, Cai M, Li ML, Zheng C. Herpes simplex virus 1 counteracts viperin via its virion host shutoff protein UL41. J Virol. (2014) 88:12163-6. doi: 10.1128/JVI.01380-14

118. Su C, Zhang J, Zheng C. Herpes simplex virus 1 UL41 protein abrogates the antiviral activity of hZAP by degrading its mRNA. Virol J. (2015) 12:203. doi: 10.1186/s12985-015-0433-y

119. Jiang Z, Su C, Zheng C. Herpes simplex virus 1 tegument protein UL41 counteracts IFIT3 antiviral innate immunity. J Virol. (2016) 90:11056-61. doi: 10.1128/JVI.01672-16

120. Helen LZ, Rui M, George B, Colin MC. Herpes simplex virus 1 counteracts tetherin restriction via its virion host shutoff activity. J Virol. (2013) 87:13115-23. doi: 10.1128/JVI.02167-13

121. Sciortino MT, Parisi T, Siracusano G, Mastino A, Taddeo B, Roizman B. The virion host shutoff RNase plays a key role in blocking the activation of protein kinase $\mathrm{R}$ in cells infected with herpes simplex virus 1. J Virol. (2013) 87:3271-6. doi: 10.1128/JVI.03049-12

122. Sànchez R, Mohr I. Inhibition of cellular $2^{\prime}-5^{\prime}$ oligoadenylate synthetase by the herpes simplex virus type 1 Us11 protein. J Virol. (2007) 81:3455-64. doi: 10.1128/JVI.02520-06

123. Ishioka K, Ikuta K, Sato Y, Kaneko H, Sorimachi K, Fukushima E, et al. Herpes simplex virus type 1 virion-derived US11 inhibits type 1 interferoninduced protein kinase R phosphorylation. Microbiol Immunol. (2013) 57:426-36. doi: 10.1111/1348-0421.12048

124. Chin KC, Cresswell P. Viperin (cig5), an IFN-inducible antiviral protein directly induced by human cytomegalovirus. ProcNatlAcadSci USA. (2001) 98:15125-30. doi: 10.1073/pnas.011593298

125. Hinson ER, Joshi NS, Chen JH, Rahner C, Jung YW, Wang X, et al. Viperin is highly induced in neutrophils and macrophages during acute and chronic lymphocytic choriomeningitis virus infection. J Immunol. (2010) 184:5723-31. doi: 10.4049/jimmunol.0903752

126. Tortorec A, Willey S, Neil SJ. Antiviral inhibition of enveloped virus release by tetherin /BST-2:actionandcounteraction. Viruses. (2011) 3:520-40. doi: $10.3390 / v 3050520$

127. Radaeva S, Jaruga B, Hong F, Kim WH, Fan S, Cai H, et al. Interferon-alpha activates multiple STAT signals and down-regulates cMet in primary human hepatocytes. Gastroenterology. (2002) 122:1020-34. doi: 10.1053/gast.2002.32388

128. Abbas YM, Pichlmair A, Gorna MW, Superti-Furga G, Nagar B. Structural basis for viral $5^{\prime}$-PPP-RNA recognition by human IFIT proteins. Nature. (2013) 494:60-4. doi: 10.1038/nature11783

129. Samuel CE. Antiviral actions of interferons. Clin Microbiol Rev. (2001) 14:778-809. doi: 10.1128/CMR.14.4.778-809.2001

130. Zhang $\mathrm{P}$, Su C, Jiang Z, Zheng C. Herpes simplex virus 1 UL41 protein suppresses the IRE1/XBP1 signal pathway of the unfolded protein response via its RNase activity. J Virol. (2017) 91:e02056-16. doi: 10.1128/JVI.02056-16

131. de Weerd NA, Samarajiwa SA, Hertzog PJ. Type I interferon 491 receptors: biochemistry and biological functions. J Biol Chem. (2007) 492:20053-7. doi: 10.1074/jbc.R700006200

132. Toshitkatsu H, Akihiko Y. Regulation of cytokine signaling and inflammation. Cytokine Growth Factor Rev. (2002) 13 413-21. doi: 10.1016/S1359-6101(02)00026-6

133. Lin HW, Hsu WL, Chang YY, Jan MS, Wong ML, Chang TJ. Role of the UL41 protein of pseudorabies virus in host shutoff, pathogenesis and induction of TNF- $\alpha$ expression. J Vet Med Sci. (2010) 72:1179-87. doi: 10.1292/jvms.10-0059

134. Suzutani T, Nagamine M, Shibaki T, Ogasawara M, Yoshida I, Daikoku T. The role of the UL41 gene of herpes simplex virus type 1 in evasion of non-specific host defence mechanisms during primary infection. J Gen Virol. (2000) 81(Pt 7):1763-71. doi: 10.1099/0022-1317-817-1763

135. Fakioglu E, Wilson SS, Mesquita PM, Hazrati E, Cheshenko N, Blaho JA, et al. Herpes simplex virus downregulates secretory leukocyte protease inhibitor: a novel immune evasion mechanism. J Virol. (2008) 82:9337-44. doi: 10.1128/JVI.00603-08

136. Sato Y, Koshizuka T, Ishibashi K, Hashimoto K, Ishioka K, Ikuta K, et al. Involvement of herpes simplex virus type $1 \mathrm{UL} 13$ protein kinase in induction of SOCS genes, the negative regulators of cytokine signaling. Microbiol Immunol. (2017) 61:159-67. doi: 10.1111/1348-0421.12483 
137. Ma Y, Zeng Q, Wang M, Cheng A, Jia R, Yang Q, et al. US10 protein is crucial but not indispensable for duck enteritis virus infection in vitro. Sci Rep. (2018) 8:16510. doi: 10.1038/s41598-018-34503-7

138. Yasukawa H. The JAK-binding protein JAB inhibits Janus tyrosine kinase activity through binding in the activation loop. EMBO J. (1999) 18:1309-20. doi: 10.1093/emboj/18.5.1309

139. Naka T, Fujimoto $M$, Tsutsui $H$, Yoshimura A. Negative regulation of cytokine and TLR signalings by SOCS and others. Adv Immunol. (2005) 87:61-122. doi: 10.1016/S0065-2776(05)87003-8

140. Ea CK, Deng L, Xia ZP, Pineda G, Chen ZJ. Activation of IKK by TNF alpha requires site-specific ubiquitination of RIP1 and polyubiquitin binding by NEMO. Mol Cell. (2006) 22:245-57. doi: 10.1016/j.molcel.2006.03.026

141. Sergerie Y, Rivest S, Boivin G. Tumor necrosis factor-alpha and interleukin-1 beta play a critical role in the resistance against lethal herpes simplex virus encephalitis. J Infect Dis. (2007). 196:853-60. doi: 10.1086/520094

142. Jana NK, Gray LR, Shugars DC. Human immunodeficiency virus type 1 stimulates the expression and production of secretory leukocyte protease inhibitor (SLPI) in oral epithelial cells: a role for SLPI in innate mucosal immunity. J Virol. (2005) 79:6432-40. doi: 10.1128/JVI.79.10.6432-6440.2005

143. Harada A, Sekido N, Akahoshi T, Wada T, Mukaido N, Matsushima K. Essential involvement of interleukin-8 (IL-8) in acute inflammation. J Leukoc Biol. (1994) 56:559-64. doi: 10.1002/jlb.56.5.559

144. van de Weijer ML, Luteijn RD, Wiertz EJ. Viral immune evasion: lessons in MHC class I antigen presentation. Semin Immunol. (2015) 27:125-13. doi: 10.1016/j.smim.2015.03.010

145. Green BJ, Clark GJ, Hart DN. The CMRF-35 mAb recognizes a second leukocyte membrane molecule with a domain similar to the poly Ig receptor. Int Immunol. (1998) 10:891-9. doi: 10.1093/intimm/10.7.891

146. Lankry D, Rovis TL, Jonjic S, Mandelboim O. The interaction between CD300a and phosphatidylserine inhibits tumor cell killing by NK cells. Eur J Immunol. (2013) 43:2151-61. doi: 10.1002/eji.201343433

147. Cannon JP, O’Driscoll M, Litman GW. Specific lipid recognitionis a general feature of CD300 and TREM molecules. Immunogenetics. (2012) 64:39-47. doi: 10.1007/s00251-011-0562-4

148. Grauwet K, Vitale M, De Pelsmaeker S, Jacob T, Laval K, Moretta L, et al. Pseudorabies virus US3 protein kinase protects infected cells from NK cellmediated lysis via increased binding of the inhibitory NK cell receptor CD300a. J Virol. (2016) 90:1522-33. doi: 10.1128/JVI.02902-15

149. Weitzman MD, Lilley CE, Chaurushiya MS. Genomes in conflict: maintaining genome integrity during virus infection. Annu Rev Microbiol. (2010) 64:61-81. doi: 10.1146/annurev.micro.112408.134016
150. Lilley CE, Chaurushiya MS, Boutell C, Everett RD, Weitzman MD. The intrinsic antiviral defense to incoming HSV-1 genomes includes specific DNA repair proteins and is counteracted by the viral protein ICPO. PLoS Pathog. (2011) 7:e1002084. doi: 10.1371/journal.ppat.1002084

151. Lilley CE, Chaurushiya MS, Boutell C, Landry S, Suh J, Panier S, et al. A viral E3 ligase targets RNF8 and RNF168 to control histone ubiquitination and DNA damage responses. EMBO J. (2010) 29:943-55. doi: 10.1038/emboj.2009.400

152. Shaffer AL, Shapiro-Shelef M, Iwakoshi NN, Lee AH, Qian SB, Zhao H, et al. $\mathrm{XBP} 1$, downstream of Blimp-1, expands the secretory apparatus and other organelles, and increases protein synthesis in plasma cell differentiation. Immunity. (2004) 21:81-93. doi: 10.1016/j.immuni.2004.06.010

153. Burnett HF, Audas TE, Liang G, Lu RR. Herpes simplex virus-1 disarms the unfolded protein response in the early stages of infection. Cell Stress Chaperones. (2012) 17:473-83. doi: 10.1007/s12192-012-0324-8

154. Hetz C, Martinon F, Rodriguez D, Glimcher LH. The unfolded protein response: integrating stress signals through the stress sensor IRE1 $\alpha$. Physiol Rev. (2011) 91:1219-43. doi: 10.1152/physrev.00001.2011

155. Sidrauski C, Walter P. The transmembrane kinase Irelp is a site-specific endonuclease that initiates mRNA splicing in the unfolded protein response. Cell. (1997) 90:1031-9. doi: 10.1016/S0092-8674(00)80369-4

156. Lee AH, Iwakoshi NN, Glimcher LH. XBP-1 regulates a subset of endoplasmic reticulum resident chaperone genes in the unfolded protein response. Mol Cell Biol. (2003) 23:7448-59. doi: 10.1128/MCB.23.21.7448-7459.2003

157. Zhang R, Xu A, Qin C, Zhang Q, Chen S, Lang Y, et al. Pseudorabies virus dUTPase UL50 induces lysosomal degradation of type I interferon receptor 1 and antagonizes the alpha interferon response. J Virol. (2017) 91:E01148-17. doi: 10.1128/JVI.01148-17

Conflict of Interest Statement: The authors declare that the research was conducted in the absence of any commercial or financial relationships that could be construed as a potential conflict of interest.

Copyright (c) 2019 Yang, Wang, Cheng, Yang, Wu, Jia, Liu, Zhu, Chen, Zhang, Zhao, Huang, Wang, Xu, Chen, Zhu, Luo, Liu, Yu, Zhang, Tian, Pan, Rehman and Chen. This is an open-access article distributed under the terms of the Creative Commons Attribution License (CC BY). The use, distribution or reproduction in other forums is permitted, provided the original author(s) and the copyright owner(s) are credited and that the original publication in this journal is cited, in accordance with accepted academic practice. No use, distribution or reproduction is permitted which does not comply with these terms. 